\title{
Molecular analysis of a high-mass prestellar core candidate in W43-MM1
}

 \\ ${ }^{1}$ Laboratoire d' astrophysique de Bordeaux, Université de Bordeaux, CNRS, B18N, allée Geoffroy Saint-Hilaire, 33615 Pessac, France \\ e-mail: jordan.molet@u-bordeaux.fr \\ ${ }^{2}$ Université Grenoble Alpes, CNRS, Institut de Planétologie et d'Astrophysique de Grenoble, 38000 Grenoble, France \\ ${ }^{3}$ Laboratoire de Physique de l'École normale supérieure, ENS, Université PSL, CNRS, Sorbonne Université, Université \\ Paris-Diderot, Sorbonne Paris Cité, Paris, France \\ ${ }^{4}$ LERMA, Observatoire de Paris, PSL Research University, CNRS, Sorbonne Université, UPMC Université Paris 06 , \\ 75231 Paris, France \\ 5 AIM Paris-Saclay Département d'Astrophysique, CEA, CNRS, Univ. Paris Diderot, CEA-Saclay, \\ 91191 Gif-sur-Yvette Cedex, France \\ ${ }^{6}$ Departamento de Astronomía de Chile, Universidad de Chile, Santiago, Chile
}

Received 19 March 2019 / Accepted 11 May 2019

\begin{abstract}
Context. High-mass analogues of low-mass prestellar cores are searched for to constrain the models of high-mass star formation. Several high-mass cores, at various evolutionary stages, have been recently identified towards the massive star-forming region W43MM1 and amongst them a high-mass prestellar core candidate.

Aims. We aim to characterise the chemistry in this high-mass prestellar core candidate, referred to as W43-MM1 core \#6, and its environment.

Methods. Using ALMA high-spatial resolution data of W43-MM1, we have studied the molecular content of core \#6 and a neighbouring high-mass protostellar core, referred to as \#3, which is similar in size and mass to core \#6. We first subtracted the continuum emission using a method based on the density distribution of the intensities on each pixel. Then, from the distribution of detected molecules, we identified the molecules centred on the prestellar core candidate (core \#6) and those associated to shocks related to outflows and filament formation. Then we constrained the column densities and temperatures of the molecules detected towards the two cores.

Results. While core \#3 appears to contain a hot core with a temperature of about $190 \mathrm{~K}$, core \#6 seems to have a lower temperature in the range from 20 to $90 \mathrm{~K}$ from a rotational diagram analysis. We have considered different source sizes for core \#6 and the comparison of the abundances of the detected molecules towards the core with various interstellar sources shows that it is compatible with a core of size 1000 au with $T=20-90 \mathrm{~K}$ or a core of size 500 au with $T \sim 80 \mathrm{~K}$.

Conclusions. Core \#6 of W43-MM1 remains one of the best high-mass prestellar core candidates even if we cannot exclude that it is at the very beginning of the protostellar phase of high-mass star formation.
\end{abstract}

Key words. stars: formation - stars: massive - ISM: abundances - ISM: molecules - radio lines: ISM

\section{Introduction}

Understanding high-mass stars $\left(M>8 M_{\odot}\right)$ is crucial in modern astrophysics since their energy budget towards the interstellar medium is the most important contribution coming from stars. They form in massive dense cores of $\sim 100 M_{\odot}$ within $\sim 0.1 \mathrm{pc}$ (Motte et al. 2007; Bontemps et al. 2010), by processes far less understood than for low-mass stars. Whereas low-mass stars have clear distinct phases of evolution from prestellar cores to young stars, we do not know if a prestellar core phase also exists for high-mass stars. While the UV radiation pressure problem (Wolfire \& Cassinelli 1987) is mostly solved in most recent 3D modelling, two competitive models remain: the "core-fed" model (e.g. McKee \& Tan 2003) and the "clump-fed" model (e.g. Bonnell \& Bate 2006; Smith et al. 2009; Vázquez-Semadeni et al. 2017). The first model supposes the existence of starless massive dense cores, whereas, for the second one, low-mass prestellar cores can become high-mass protostars by collecting surrounding gas. The observation of a high-mass prestellar core is challenging due to the lower number of high-mass stars compared to the number of low-mass stars (only $\sim 1 \%$ of the Galactic stellar population) and the short duration of the hypothetical prestellar phase $\left(\sim 10^{4}-10^{5} \mathrm{yr}\right.$; Tigé et al. 2017 , and references therein). Motte et al. (2018a) and Louvet (2018) list the current high-mass prestellar core candidates: CygX-N53-MM2 (Duarte-Cabral et al. 2014), G11.92-0.61-MM2 (Cyganowski et al. 2014), G11.11-P6-SMA1 (Wang et al. 2014), G028CA9 (Kong et al. 2017), and W43-MM1\#6 (Nony et al. 2018). No detailed study about their molecular content has been done so far. We investigate here the latter one, W43-MM1\#6.

The W43-MM1 ridge is a massive molecular cloud of $2 \times 10^{4} M_{\odot}$ contained in $6 \mathrm{pc}^{2}$. It is the main submillimeter fragment of the W43 complex (Motte et al. 2003; Nguyen-Luong et al. 2013), located at the end of the Galactic bar at a distance of $5.5 \mathrm{kpc}$ from the Sun (Nguyen Luong et al. 2011; Zhang et al. 2014). W43-MM1 is associated to $\mathrm{OH}, \mathrm{CH}_{3} \mathrm{OH}$, and $\mathrm{H}_{2} \mathrm{O}$ masers (respectively Braz \& Epchtein 1983; Walsh et al. 1998; Valdettaro et al. 2001), which are high-mass stellar activity signposts (Motte et al. 2003). At $0.05 \mathrm{pc}$ resolution, W43-MM1 appears as a mini-starburst cluster with a high star formation 
rate of $6000 M_{\odot} \mathrm{Myr}^{-1}$ and N1a as the most massive dense core (Louvet et al. 2014). Louvet et al. (2016) identified a largescale shock $(\sim 5 \mathrm{pc})$ along the filament, consistent with numerical models of a collision of two giant molecular clouds (e.g. Wu et al. 2017), and intermediate-scale shocks ( $\sim 0.2 \mathrm{pc})$ tracing protostellar outflows. The presence of small-scale shocks due to the collision of gas inflows on the cores has been suggested but not observed yet probably because of the limited sensitivity and/or angular resolution. More recently, Motte et al. (2018b) identified a large population of cores with $\sim 2000$ au typical sizes, and numerous high-mass cores. This suggests that W43-MM1 is one of the youngest and richest clusters of high-mass cores in the Milky Way. This sample is thus excellent to search for a high-mass prestellar core (Nony et al. 2018).

Two neighbouring cores with the same size and mass have been studied by Nony et al. (2018). The first core, identified as core \#3, has clear outflows traced by $\mathrm{SiO}(5-4)$ and $\mathrm{CO}(2-1)$ transitions and a line forest seen over the continuum band, which qualifies it as a protostellar object. Core \#6 in contrast does not show any outflow and just a few lines are seen in the continuum band; it is thus a good high-mass prestellar core candidate. During the evolution from the molecular cloud to the formation of the protostar, the composition of the gas evolves (e.g. Gerner et al. 2014). The formation and destruction of molecules depend on the density of the environment, temperature, time, and dynamics. A rise in temperature will allow molecules to desorb from the grain mantles to the gas phase and thus to be detectable by rotational spectroscopy. Complex organic molecules (COMs) have already been detected in both high-mass and low-mass star-forming regions. The typical radius of hot corinos, where the dust temperature is $100 \mathrm{~K}$, is $<100 \mathrm{au}$, while it is a few thousands au for hot cores (e.g. Herbst \& van Dishoeck 2009). We propose here to determine the nature of the W43-MM1 high-mass core \#6, constraining the physical and chemical conditions of the core from the observed abundances and excitation temperatures of the detected molecules.

The article is organised as follows. We present the data and the method used to subtract the continuum in Sect. 2. In Sect. 3, we analyse the molecular content of cores \#3 and \#6. We study the distribution of the molecules to select those that are directly related to core \#6 and we estimate their temperature and column densities. In Sect. 4 we compare our results with other star-forming regions and discuss the nature of cores \#3 and \#6.

\section{Observations and data reduction}

\subsection{Data set}

Observations were carried out in Cycle 2 (project \#2013.1.01365.S) and Cycle 3 (\#2015.1.01273.S), with the ALMA $12 \mathrm{~m}$ and ACA $7 \mathrm{~m}$ arrays. W43-MM1 was imaged in band 6 (between 216 and $234 \mathrm{GHz}$ ) with a $78^{\prime \prime} \times 53^{\prime \prime}$ $(2.1 \mathrm{pc} \times 1.4 \mathrm{pc})$ mosaic composed of 33 fields with the $12 \mathrm{~m}$ array and 11 fields with ACA. The total bandwidth is $4.8 \mathrm{GHz}$ made of two continuum bands and seven narrow bands centred on lines of interest, with a spectral resolution ranging from 122 to $976 \mathrm{kHz}\left(0.17\right.$ to $\left.1.26 \mathrm{~km} \mathrm{~s}^{-1}\right)$ and a spatial resolution of $\sim 0.44^{\prime \prime}$ ( $\left.2400 \mathrm{au}\right)$ (see Table 1). The continuum band centred on $232.4 \mathrm{GHz}$ is taken from Cycle 3 data and has a lower spatial resolution $\left(\sim 0.57^{\prime \prime}\right.$ or $\left.\sim 3200 \mathrm{au}\right)$. Data reduction was made with CASA 4.7.2. (McMullin et al. 2007). The cleaning was performed with a 0.5 Briggs robustness weighting, using the multiscale option and with a threshold of $\sim 1 \sigma$ cropped on a
Table 1. Parameters of the ALMA spectral windows.

\begin{tabular}{lccccc}
\hline \hline \multirow{2}{*}{$\begin{array}{l}\text { Spectral } \\
\text { windows }\end{array}$} & \multirow{2}{*}{$\begin{array}{c}v_{\mathrm{obs}} \\
(\mathrm{GHz})\end{array}$} & Bandwidth & \multicolumn{2}{c}{ Resolution } & rms \\
\cline { 4 - 5 } & $(\mathrm{MHz})$ & $\left({ }^{\prime \prime} \times{ }^{\prime \prime}\right)$ & $\left(\mathrm{km} \mathrm{s}^{-1}\right)$ & $(\mathrm{K})$ \\
\hline $\mathrm{OC}^{33} \mathrm{~S}$ & 216.076 & 234 & $0.55 \times 0.40$ & 0.17 & 0.37 \\
$\mathrm{SiO}$ & 217.033 & 234 & $0.54 \times 0.39$ & 0.34 & 0.42 \\
$\mathrm{H}_{2} \mathrm{CO}$ & 218.150 & 234 & $0.54 \times 0.39$ & 0.17 & 0.38 \\
$\mathrm{C}^{18} \mathrm{O}$ & 219.488 & 117 & $0.53 \times 0.39$ & 0.17 & 0.49 \\
$\mathrm{SO}$ & 219.877 & 117 & $0.54 \times 0.39$ & 0.33 & 0.44 \\
$\mathrm{CO}$ & 230.462 & 469 & $0.52 \times 0.38$ & 1.27 & 0.25 \\
${ }^{13} \mathrm{CS}$ & 231.144 & 469 & $0.52 \times 0.37$ & 0.32 & 0.28 \\
Cont. 1 & 232.4 & 1875 & $0.66 \times 0.50$ & 1.26 & 0.12 \\
Cont. 2 & 233.4 & 1875 & $0.51 \times 0.36$ & 1.26 & 0.22 \\
\hline
\end{tabular}

Notes. ${ }^{(a)}$ Spectral window observed in Cycle 3. The other windows were observed in Cycle 2.

region excluding the borders of the mosaic to avoid problems of divergence.

\subsection{Continuum subtraction}

Because of the sensitivity of the current instruments, it is now difficult to find channels with no emission line over all the map to subtract the continuum in a data cube. In W43-MM1, Motte et al. (2018b) identify 131 continuum cores with masses ranging from $\sim 1 M_{\odot}$ to $\sim 100 M_{\odot}$ and line contamination between $0 \%$ and $74 \%$. The analysis of the four bright methyl formate $\left(\mathrm{CH}_{3} \mathrm{OCHO}\right)$ lines detected in the $216 \mathrm{GHz}$ band gives a velocity ranging from 94 to $102 \mathrm{~km} \mathrm{~s}^{-1}$ for the 11 main continuum cores. Due to the numerous lines in the various cores and the different velocities of the cores, line emission is present in almost all channels. It is thus necessary to use a method of continuum subtraction that handles each pixel independently. We developed a method similar to the one presented in Jørgensen et al. (2016), using the density distribution of the channel intensities on each pixel. The profile of the distribution is composed of a Gaussian part due to the noise, and a tail towards high intensities associated with the molecular emission. The Gaussian noise distribution peaks on the true continuum value, but the peak of the observed distribution can be displaced due to the contribution of the tail. The best way to obtain a correct continuum value with the density profile method is discussed in Sanchez-Monge et al. (2017), and the corrected sigma-clipping method (cSCM) seems to be the most effective using their STATCONT algorithm. To properly treat the statistical behaviour of the tail, we use the exponentially modified Gaussian (EMG) function (Grushka 1972), which is the convolution between a Gaussian and an exponential decay,

$f_{\mathrm{EMG}}(x)=A \sigma \lambda \sqrt{\frac{\pi}{2}} \exp \left[\lambda \frac{2 \mu+\lambda \sigma^{2}-2 x}{2}\right] \operatorname{erfc}\left(\frac{\mu+\lambda \sigma^{2}-x}{\sqrt{2} \sigma}\right)$,

where $A$ is the peak amplitude, $\sigma$ the variance of the Gaussian, $\lambda$ the relaxation rate of the exponential modifier, $\mu$ the centre of the Gaussian, and erfc the complementary error function.

We compared our EMG method with the cSCM from STATCONT, using synthetic spectra with parameters comparable to our data. Our method is about 20 times faster than STATCONT and we estimated a relative error on the continuum of $\pm 2 \%$ with the EMG method fit versus $\pm 5 \%$ for the cSCM. Figure 1 


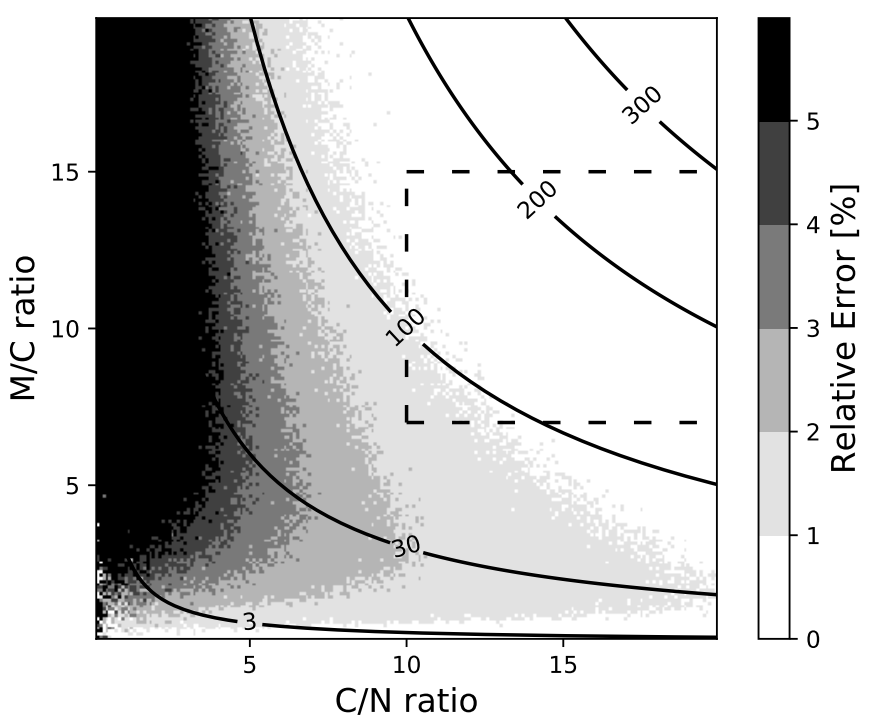

Fig. 1. Estimation of the relative error on the continuum level determination, depending on the molecular/continuum (M/C) ratio and continuum/noise $(\mathrm{C} / \mathrm{N})$ ratio. The black lines represent the $\mathrm{M} / \mathrm{N}$ ratio. The typical ratios from the core \#3 pixels are included in the dashed box. Each pixel is the average of the errors obtained from 20 synthetic spectra of 1000 channels with 100 random molecular Gaussian lines that follow a power law comparable to the observed data.

presents the estimation of the error depending on the following parameters: the continuum level, the maximum of the molecular emission and the noise level. We find that the EMG method is well adapted for this kind of molecular distribution. Part of the derived continuum map is presented in Fig. 2. Comparing with the line-contaminated continuum map of Motte et al. (2018b), derived from the integration of the full continuum band without getting rid of molecular lines, the positions of the cores are the same but the signal on their map is overestimated on average by $\sim 20 \%$ on continuum cores and up to $60 \%$ for cores \#1 and \#4. As for the line-free continuum map of Motte et al. (2018b), it is consistent, within $10 \%$, with the EMG continuum image but it is 1.2 times noisier.

\section{Results and analysis}

Out of the 13 high-mass cores with $M>16 M_{\odot}$, identified at $1.3 \mathrm{~mm}$ by Motte et al. (2018b) in the W43-MM1 protocluster, we focus in this paper on the high-mass cores at the south-western tip of the main filament (see Fig. 1 of Nony et al. 2018) and we follow the same nomenclature. Table 2 lists the main characteristics of the four high-mass cores identified in the continuum map (lower right panel in Fig. 2). The sizes and shapes of the cores are the same as in Motte et al. (2018b) and Nony et al. (2018) and do not change in this frequency range. We are interested in particular in the comparison of cores \#3 and \#6, which are close $(0.08 \mathrm{pc}, 16000 \mathrm{au})$, with a similar size of $1200 \mathrm{au}$ and mass of $\sim 60 M_{\odot}$. We study here their spectra, averaged spatially over the size of the continuum cores.

\subsection{Molecular content of cores \#3 and \#6}

Whereas core \#3 displays a forest of lines, much fewer lines are observed towards core \#6 (see Figs. A.1 and A.2, respectively). We first studied the molecular content of core \#3. The 25 molecules that we identified in this core, including isotopologues, are listed in Table 3, and the line parameters of all detected transitions are given in Table A.1. Out of these molecules, 17 are identified in core \#6. The line parameters of the 33 detected transitions towards core \#6 are listed in Table A.2.

Complex molecules are clearly present in core \#6 with the detection of methanol $\left(\mathrm{CH}_{3} \mathrm{OH}\right)$ and its isotopologue $\left({ }^{13} \mathrm{CH}_{3} \mathrm{OH}\right)$, acetaldehyde $\left(\mathrm{CH}_{3} \mathrm{CHO}\right)$, dimethyl ether $\left(\mathrm{CH}_{3} \mathrm{OCH}_{3}\right)$, and methyl formate $\left(\mathrm{CH}_{3} \mathrm{OCHO}\right)$. There is no clear evidence of the presence of other COMs in core \#6, except a tentative detection of the methanol isotopologue $\mathrm{CH}_{3}^{18} \mathrm{OH}$ and of formamide $\left(\mathrm{NH}_{2} \mathrm{CHO}\right)$ that only appear when the corresponding lines are stacked. For $\mathrm{CH}_{3}^{18} \mathrm{OH}$, eight lines are considered as not contaminated by other species in core \#3 and were selected for core \#6. In the same way, five lines were selected for $\mathrm{NH}_{2} \mathrm{CHO}$. Some of the molecules detected towards core \#6 seem to be directly associated with the continuum core, whereas the others do not peak at the centre of the core and are being interpreted as part of the large-scale features.

Molecules not directly associated to core \#6. For seven of the species detected in core \#6, the large-scale view shows that the distribution of these molecules is not only centred on the continuum cores (see Fig. 2). On small scales, those molecules clearly peak at the north of core \#6 (e.g. SiO) or belong to the environment (see DCN map). On large scales, $\mathrm{CO}$ and $\mathrm{SiO}$ mainly trace the outflows from core \#3 and \#9, which have been already analysed by Nony et al. (2018). SO, $\mathrm{H}_{2}^{13} \mathrm{CO}$, and DCN follow the filament observed in continuum emission.

Molecules centred on core \#6. The other ten identified species are clearly centred on the continuum core (see Fig. 3). This suggests that part of the emission of these molecules is not associated to the large-scale shocks expected in a cloud forming though collision or along protostellar outflows, but is directly linked to the presence of the core. The distribution of these molecules in the neighbouring core \#3 is also centred on the continuum peak as shown in Fig. 4. We used a Gaussian fit to derive a deconvolved size of the molecular emission, which appears to be typically close to the size of the beam for all ten molecules observed in core \#6. The results are comparable for the two cores (see Table 3), except for the $\mathrm{C}^{18} \mathrm{O}$ emission, which is three times more extended than the continuum extension of core \#3. We note a recurrent small offset $\left(<0.2^{\prime \prime}\right.$, i.e. less than half of the beam) of the molecular emission with respect to the continuum peak, towards the south for core \#3 and towards the east for core \#6 (see Fig. 5).

\subsection{Critical density and opacity}

The critical densities are estimated as $n_{\text {crit }}=A_{\mathrm{ij}} / q_{\mathrm{ij}}$ with $A_{\mathrm{ij}}$ the Einstein coefficient and $q_{\mathrm{ij}}$ the collision rate coefficient. The values of the critical densities for the individual transitions of the molecules, available in the Leiden Atomic and Molecular Database $^{1}$ (Schöier et al. 2005), are indicated in Tables A.1 and A.2. We find values between $\sim 10^{4}$ and $10^{7} \mathrm{~cm}^{-3}$ for our lines, which are lower than the obtained $n_{\mathrm{H}_{2}}$ values of the cores $\left(\sim 10^{9} \mathrm{~cm}^{-3}\right.$, see Table 2$)$. In the following we will hence assume that local thermodynamical equilibrium (LTE) conditions are verified.

In general, isotopologues are less likely to be optically thick than their main isotopologue because of their lower abundances. Considering a distance of W43-MM1 from the Galactic centre of $4.5 \mathrm{kpc}$ (Zhang et al. 2014), we take for the isotopic ratios:

1 https://home.strw.leidenuniv.nl/ moldata/ 
$\left[\mathrm{K} \mathrm{km} \cdot \mathrm{s}^{-1}\right]$
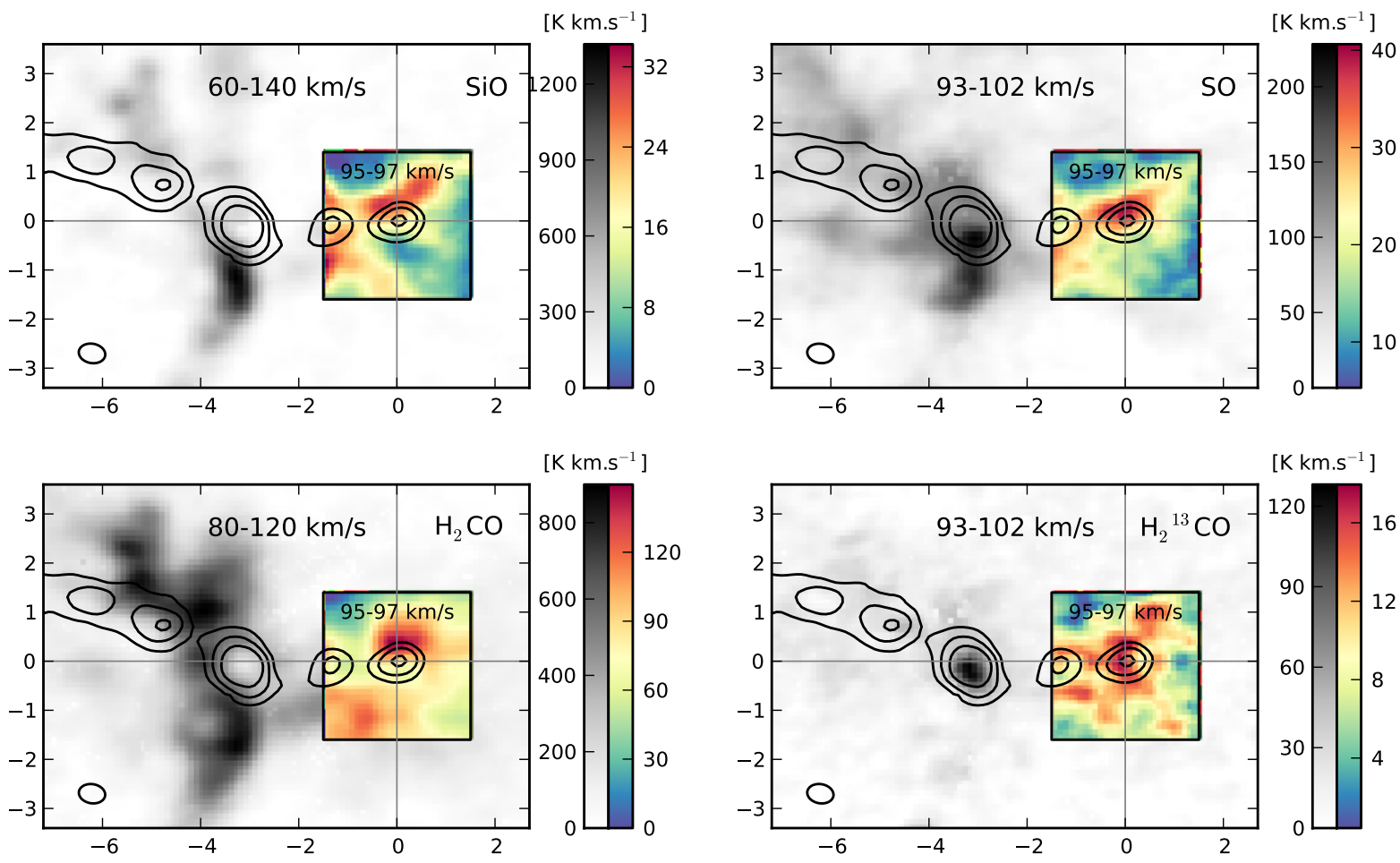

$\left[\mathrm{K} \mathrm{km} \cdot \mathrm{s}^{-1}\right]$
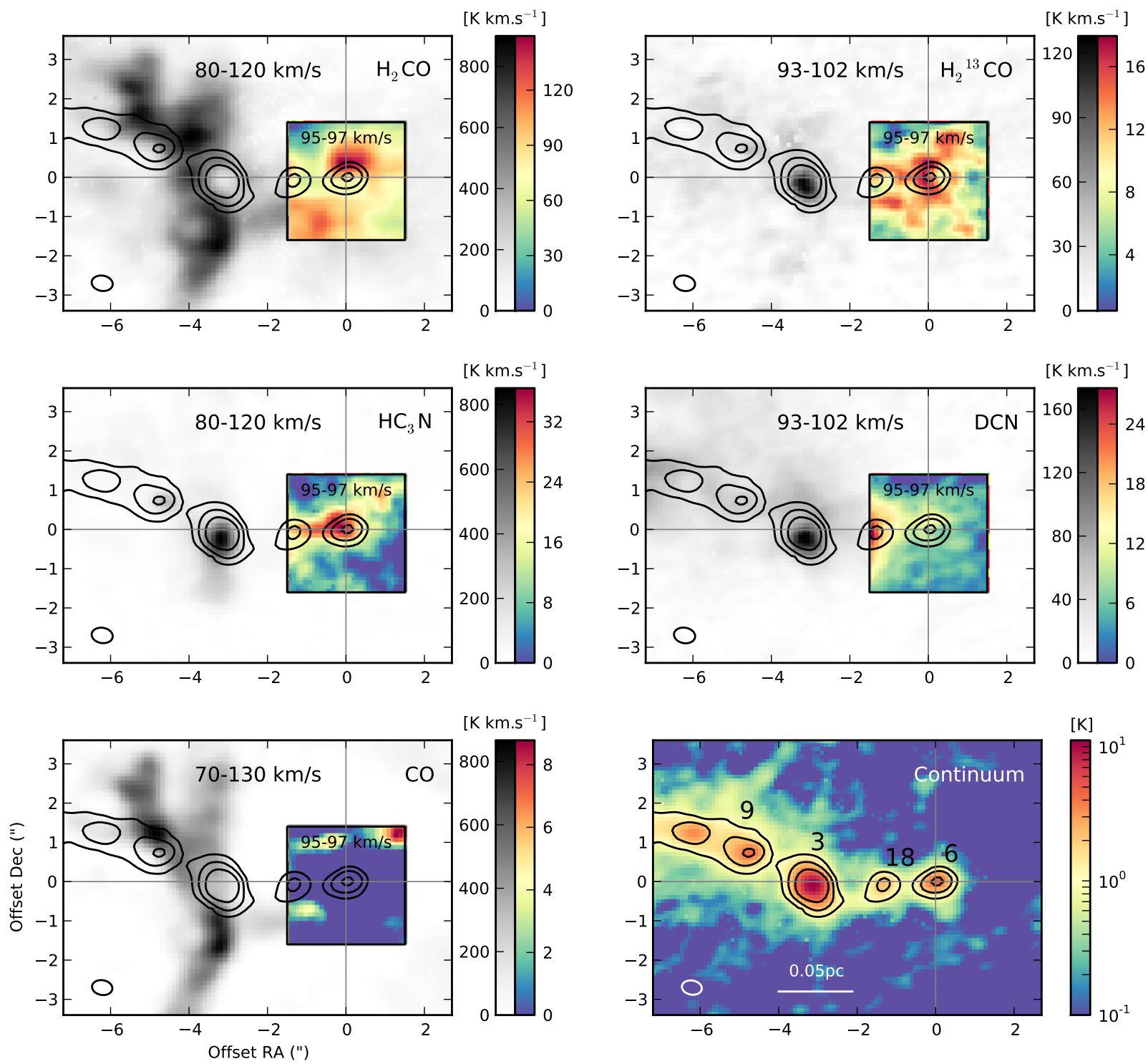

Fig. 2. Velocity integrated maps of the molecules that do not peak on core \#6. The velocity range is indicated on the top of each box. For each molecule, grey scale images correspond to the large-scale map with large dynamics in intensity, while the colour maps focus on a narrower region around core \#6 with smaller dynamics in intensity (as indicated by the two wedges on the right side of each panel). Temperature is the main beam brightness temperature $T_{\mathrm{mb}}$. The continuum map obtained from the Cont. 2 spectral window data is plotted in the bottom right panel. The contours represent the 5-10-20 $\sigma$ continuum emission, with $5 \sigma \approx 9 \mathrm{mJy}_{\text {beam }}{ }^{-1}$. The position is relative to the centre of the continuum core \#6. The beam is represented in the bottom left corner of each map. The CO emission is completely filtered in the $95-97 \mathrm{~km} \mathrm{~s}^{-1}$ velocity range around core \#6 (see Fig. A.2), but its presence is confirmed by the $\mathrm{C}^{18} \mathrm{O}$ emission.

${ }^{12} \mathrm{C} /{ }^{13} \mathrm{C}=45 \pm 13$ (Milam et al. 2005), ${ }^{32} \mathrm{~S} /{ }^{33} \mathrm{~S}=90 \pm 30$ (Chin et al. 1996), and ${ }^{18} \mathrm{O} /{ }^{16} \mathrm{O}=327 \pm 32$ (Wilson \& Rood 1994). The detection of ${ }^{13} \mathrm{CH}_{3} \mathrm{OH}$ in core \#6 is important since the methanol is optically thick. We also preferred to use the available isotopologues of CS and OCS to avoid some underestimations of abundances. 
Table 2. Characteristics of the cores located at the tip of the main filament (from Motte et al. 2018b).

\begin{tabular}{cccccccc}
\hline \hline $\begin{array}{c}\text { Core } \\
\#\end{array}$ & $\begin{array}{c}\text { RA } \\
(\mathrm{J} 2000)\end{array}$ & $\begin{array}{c}\text { Dec } \\
(\mathrm{J} 2000)\end{array}$ & $\begin{array}{c}\text { Size } \\
(“ \times ”)\end{array}$ & $\begin{array}{c}F W H M \\
(\mathrm{au})\end{array}$ & $\begin{array}{c}M_{\text {core }} \\
\left(M_{\odot}\right)\end{array}$ & $\begin{array}{c}n_{\mathrm{H} 2} \\
\left(\times 10^{9} \mathrm{~cm}^{-3}\right)\end{array}$ & $\begin{array}{c}T_{\text {dust }} \\
(\mathrm{K})\end{array}$ \\
\hline 3 & $18^{\mathrm{h}} 47^{\mathrm{m}} 46.37$ & $-1^{\circ} 54^{\prime} 33^{\prime \prime} \cdot 41$ & $0.52 \times 0.47$ & 1200 & $59 \pm 2$ & $7.6 \pm 0.3$ & $45 \pm 1$ \\
6 & $18^{\mathrm{h}} 47^{\mathrm{m}} 46.16$ & $-1^{\circ} 54^{\prime} 33^{\prime \prime} \cdot 30$ & $0.55 \times 0.45$ & 1300 & $56 \pm 9$ & $6.6 \pm 0.1$ & $23 \pm 2$ \\
9 & $18^{\mathrm{h}} 47^{\mathrm{m}} 46.48$ & $-1^{\circ} 54^{\prime} 32^{\prime \prime} 54$ & $0.63 \times 0.45$ & 1600 & $17.8 \pm 0.9$ & $1.0 \pm 0.1$ & $50 \pm 1$ \\
18 & $18^{\mathrm{h}} 47^{\mathrm{m}} 46.25$ & $-1^{\circ} 54^{\prime} 33^{\prime \prime} \cdot 41$ & $0.93 \times 0.45$ & 2600 & $28 \pm 4$ & $0.4 \pm 0.1$ & $23 \pm 2$ \\
\hline
\end{tabular}

Table 3. Excitation temperatures and column densities of the detected molecules towards cores \#3 and \#6 derived for a core of the beam size.

\begin{tabular}{|c|c|c|c|c|c|c|c|c|c|c|}
\hline \multirow[b]{2}{*}{ Molecule } & \multicolumn{5}{|c|}{ Core \#3 } & \multicolumn{5}{|c|}{ Core \#6 } \\
\hline & $\begin{array}{c}\bar{v} \\
\left(\mathrm{~km} \mathrm{~s}^{-1}\right)\end{array}$ & $\begin{array}{c}\overline{\Delta v} \\
\left(\mathrm{~km} \mathrm{~s}^{-1}\right)\end{array}$ & $\begin{array}{c}N_{\text {tot }} \\
\left(\mathrm{cm}^{-2}\right)\end{array}$ & $\begin{array}{l}T_{\mathrm{ex}} \\
(\mathrm{K})\end{array}$ & $\begin{array}{c}\text { Size } \\
\left({ }^{\prime \prime} \times{ }^{\prime \prime}\right)\end{array}$ & $\begin{array}{c}\bar{v} \\
\left(\mathrm{~km} \mathrm{~s}^{-1}\right)\end{array}$ & $\begin{array}{c}\overline{\Delta v} \\
\left(\mathrm{~km} \mathrm{~s}^{-1}\right)\end{array}$ & $\begin{array}{c}N_{\text {tot }} \\
\left(\mathrm{cm}^{-2}\right)\end{array}$ & $\begin{array}{l}T_{\mathrm{ex}} \\
(\mathrm{K})\end{array}$ & $\begin{array}{c}\text { Size } \\
\left({ }^{\prime \prime} \times{ }^{\prime \prime}\right)\end{array}$ \\
\hline $\mathrm{C}^{18} \mathrm{O}$ & - & - & $>1.8(17)^{(a)}$ & 190 & $2.36 \times 1.17$ & - & - & - & - & $0.53 \times 0.18$ \\
\hline $\mathrm{CH}_{3} \mathrm{OH}$ & $97.1 \pm 0.1$ & $5.9 \pm 0.3$ & $4.7 \pm 0.4(17)$ & $320 \pm 80$ & $0.55 \times 0.35$ & $95.8 \pm 0.2$ & $3.3 \pm 0.4$ & $4.2 \pm 4.0(17)$ & $55 \pm 35$ & $0.54 \times 0.52$ \\
\hline${ }^{13} \mathrm{CH}_{3} \mathrm{OH}$ & $97.0 \pm 0.1$ & $5.3 \pm 0.3$ & $9.8 \pm 2.1(16)$ & $210 \pm 40$ & $0.52 \times 0.36$ & $96.5 \pm 0.2$ & $5.2 \pm 0.5$ & - & - & $<0.55 \times 0.45$ \\
\hline $\mathrm{CH}_{3} \mathrm{CHO}$ & $96.6 \pm 0.2$ & $5.6 \pm 0.7$ & $5.7 \pm 0.1(15)$ & $150 \pm 40$ & $0.68 \times 0.46$ & $95.6 \pm 0.1$ & $2.6 \pm 0.4$ & $2.6 \pm 1.9(15)$ & $30 \pm 15$ & $0.71 \times 0.54$ \\
\hline${ }^{13} \mathrm{CS}$ & $97.0 \pm 0.1$ & $5.0 \pm 0.1$ & $8.9(14)$ & 190 & $0.94 \times 0.86$ & $95.4 \pm 0.1$ & $3.4 \pm 0.3$ & - & - & $0.73 \times 0.48$ \\
\hline $\mathrm{CH}_{3} \mathrm{OCH}_{3}$ & $96.3 \pm 0.1$ & $6.7 \pm 0.3$ & $9.3 \pm 1.4(16)$ & $140 \pm 25$ & $0.61 \times 0.53$ & $95.9 \pm 0.2$ & $2.3 \pm 0.7$ & - & - & - \\
\hline $\mathrm{CH}_{3} \mathrm{OCHO}$ & $97.3 \pm 0.3$ & $4.7 \pm 0.8$ & $1.0 \pm 0.3(17)$ & $250 \pm 50$ & $0.51 \times 0.28$ & $95.7 \pm 0.2$ & $3.0 \pm 0.3$ & $7.0 \pm 4.0(15)$ & $50 \pm 30$ & $0.62 \times 0.22$ \\
\hline OCS & $96.5 \pm 0.1$ & $5.7 \pm 0.1$ & $2.2(16)$ & 190 & $0.70 \times 0.55$ & $95.7 \pm 0.1$ & $3.7 \pm 0.2$ & - & - & $0.78 \times 0.56$ \\
\hline $\mathrm{O}^{13} \mathrm{CS}$ & $97.1 \pm 0.1$ & $4.0 \pm 0.1$ & $3.3(15)$ & 190 & $0.43 \times 0.34$ & $95.1 \pm 0.2$ & $2.1 \pm 0.4$ & - & - & $<0.55 \times 0.45$ \\
\hline $\mathrm{OC}^{33} \mathrm{~S}$ & $96.6 \pm 0.1$ & $3.7 \pm 0.2$ & $1.4(15)$ & 190 & $0.49 \times 0.24$ & $95.4 \pm 0.3$ & $2.1 \pm 0.6$ & - & - & $<2.1 \times 0.22$ \\
\hline $\mathrm{SiO} v=0$ & - & - & $>5.6(14)^{(a)}$ & 190 & - & $95.8 \pm 0.3$ & $5.1 \pm 0.7$ & - & - & \\
\hline SO & $97.0 \pm 0.1$ & $5.6 \pm 0.2$ & $4.1(15)$ & 190 & - & $96.1 \pm 0.1$ & $3.2 \pm 0.3$ & - & - & \\
\hline $\mathrm{H}_{2} \mathrm{CO}$ & - & - & $>1.0(16)^{(a)}$ & 190 & - & - & - & - & - & \\
\hline $\mathrm{H}_{2}^{13} \mathrm{CO}$ & $97.2 \pm 0.1$ & $4.6 \pm 0.2$ & $2.1(15)$ & 190 & - & $96.0 \pm 0.2$ & $2.4 \pm 0.6$ & - & - & Not centred \\
\hline $\mathrm{HC}_{3} \mathrm{~N}$ & $96.6 \pm 0.1$ & $5.3 \pm 0.1$ & $5.8(14)$ & 190 & - & $96.3 \pm 0.2$ & $4.4 \pm 0.5$ & - & - & \\
\hline $\mathrm{DCN}$ & $96.8 \pm 0.1$ & $5.8 \pm 0.3$ & $3.6(14)$ & 190 & - & $95.6 \pm 0.1$ & $1.7 \pm 0.3$ & - & - & \\
\hline $\mathrm{CO}$ & - & - & $>3.0(18)^{(a)}$ & 190 & - & - & - & - & - & \\
\hline $\mathrm{CH}_{3}^{18} \mathrm{OH}$ & $97.3 \pm 0.7$ & $4.8 \pm 1.1$ & $1.6 \pm 0.8(16)$ & $170 \pm 60$ & - & & & & & \\
\hline${ }^{13} \mathrm{CH}_{3} \mathrm{CN}$ & $97.1 \pm 0.3$ & $5.1 \pm 0.7$ & $5.7 \pm 1.3(14)$ & $130 \pm 60$ & - & & & & & \\
\hline $\mathrm{HC}(\mathrm{O}) \mathrm{NH}_{2}$ & $97.3 \pm 0.4$ & $6.2 \pm 0.9$ & $1.7 \pm 0.7(15)$ & $260 \pm 120$ & - & & & & & \\
\hline $\mathrm{C}_{2} \mathrm{H}_{5} \mathrm{OH}$ & $97.3 \pm 0.4$ & $5.0 \pm 1.0$ & $2.4 \pm 0.5(16)$ & $85 \pm 20$ & - & & & & & \\
\hline $\mathrm{H}_{2} \mathrm{C}^{34} \mathrm{~S}$ & $96.8 \pm 0.3$ & $4.9 \pm 0.6$ & $1.4(15)$ & 190 & - & & & Not detected & & \\
\hline $\mathrm{CH}_{3} \mathrm{COCH}_{3}$ & $97.4 \pm 0.5$ & $4.7 \pm 0.6$ & $2.0(16)$ & 190 & - & & & & & \\
\hline $\mathrm{C}_{2} \mathrm{H}_{3} \mathrm{CN}$ & $96.2 \pm 0.3$ & $7.2 \pm 0.7$ & $2.9(15)$ & 190 & - & & & & & \\
\hline $\mathrm{C}_{2} \mathrm{H}_{5} \mathrm{CN}$ & $97.2 \pm 0.1$ & $4.9 \pm 0.4$ & $4.5 \pm 1.5(15)$ & $170 \pm 70$ & - & & & & & \\
\hline
\end{tabular}

Notes. $a(b)=a \times 10^{b} .{ }^{(a)}$ Only a lower limit of the column density can be derived for the molecules where the emission is self-absorbed or filtered by the interferometer.

\subsection{Temperatures and abundances}

The total column density $N_{\text {tot }}$ and the excitation temperature $T_{\text {ex }}$ can be obtained in LTE and optically thin conditions using the relation

$\ln \frac{N_{\mathrm{u}}}{g_{\mathrm{u}}}=\ln N_{\mathrm{tot}}-\ln Q\left(T_{\mathrm{ex}}\right)-\frac{E_{\mathrm{u}}}{k_{\mathrm{B}} T_{\mathrm{ex}}}$,

with $N_{\mathrm{u}}$ the upper level column density, $g_{\mathrm{u}}$ the degeneracy of the upper state, $Q\left(T_{\mathrm{ex}}\right)$ the partition function, and $E_{\mathrm{u}}$ the upper state energy. We assume here that the filling factor is equal to 1. In LTE conditions, the excitation temperature is identical to the kinetic temperature.

For core \#3, we could derive the column density and the excitation temperature for ten molecules out of the 25 molecules detected using rotational diagrams since we detected more than two transitions for these ten molecules. For core \#6, it was only possible for methanol, acetaldehyde, and methyl formate, which have enough detected transitions to build a rotational diagram. The rotational diagrams were performed using the CASSIS ${ }^{2}$ software (Vastel et al. 2015). The derived values are displayed in Table 3. Despite the significant uncertainties, the temperature seems to be lower for core \#6 (15-90 K) than for core \#3 $(\sim 190 \mathrm{~K})$.

The local density is high enough to reach LTE conditions, so that we could use the equation (Tielens 2005)

$N_{\mathrm{tot}}=\frac{1.94 \times 10^{3}}{A_{\mathrm{ij}}} v_{\mathrm{ij}}^{2} \int T_{\mathrm{mb}} \mathrm{d} v \frac{Q\left(T_{\mathrm{ex}}\right)}{g_{\mathrm{u}} \exp \left(-E_{\mathrm{u}} / k_{\mathrm{B}} T_{\mathrm{ex}}\right)}$, 



Fig. 3. Same as Fig. 2 but for molecules centred on core \#6.

where $N_{\text {tot }}$ is in $\mathrm{cm}^{-2}, v_{\mathrm{ij}}$ is the rest frequency in $\mathrm{GHz}$, and the only parameter coming from the observations is the integrated intensity $\int T_{\mathrm{mb}} \mathrm{d} v$ in $\mathrm{K} \mathrm{km} \mathrm{s}^{-1}$. The spectroscopic parameters come from the Cologne Database for Molecular Spectroscopy $\left(\mathrm{CDMS}^{3}\right)$ and the Jet Propulsion Laboratory ( $\mathrm{JPL}^{4}$ ) catalogue

\footnotetext{
3 https://cdms.astro.uni-koeln.de

4 http://spec.jpl.nasa.gov/
}

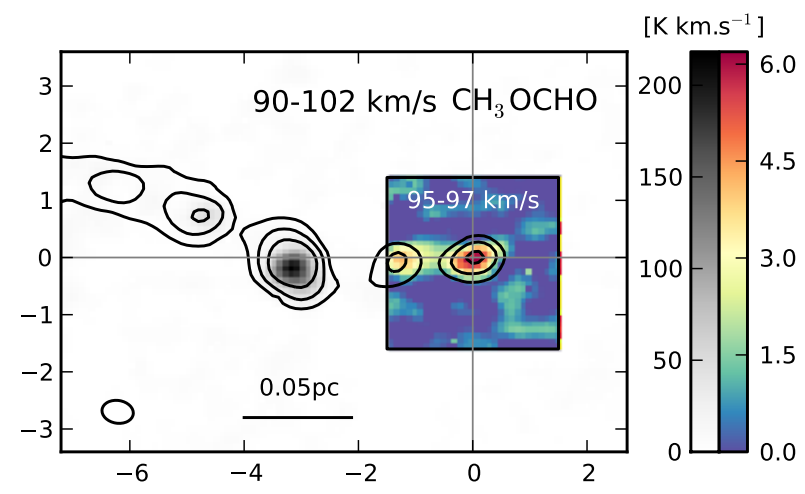

depending on the molecules (see Tables A.1 and A.2). When it was not possible to use a rotational diagram, we assumed an excitation temperature of $190 \mathrm{~K}$ for core \#3 to derive a column density with Eq. (3). These results are the inputs for the synthetic spectra in Figs. A.1 and A.2. Residuals show that only a few lines are unidentified towards core \#3. Since $\mathrm{H}_{2} \mathrm{CO}$ and $\mathrm{C}^{18} \mathrm{O}$ are self-absorbed and $\mathrm{SiO}$ and $\mathrm{CO}$ are filtered, only lower limits can be obtained and no correct synthetic spectra can be 
Core \#3
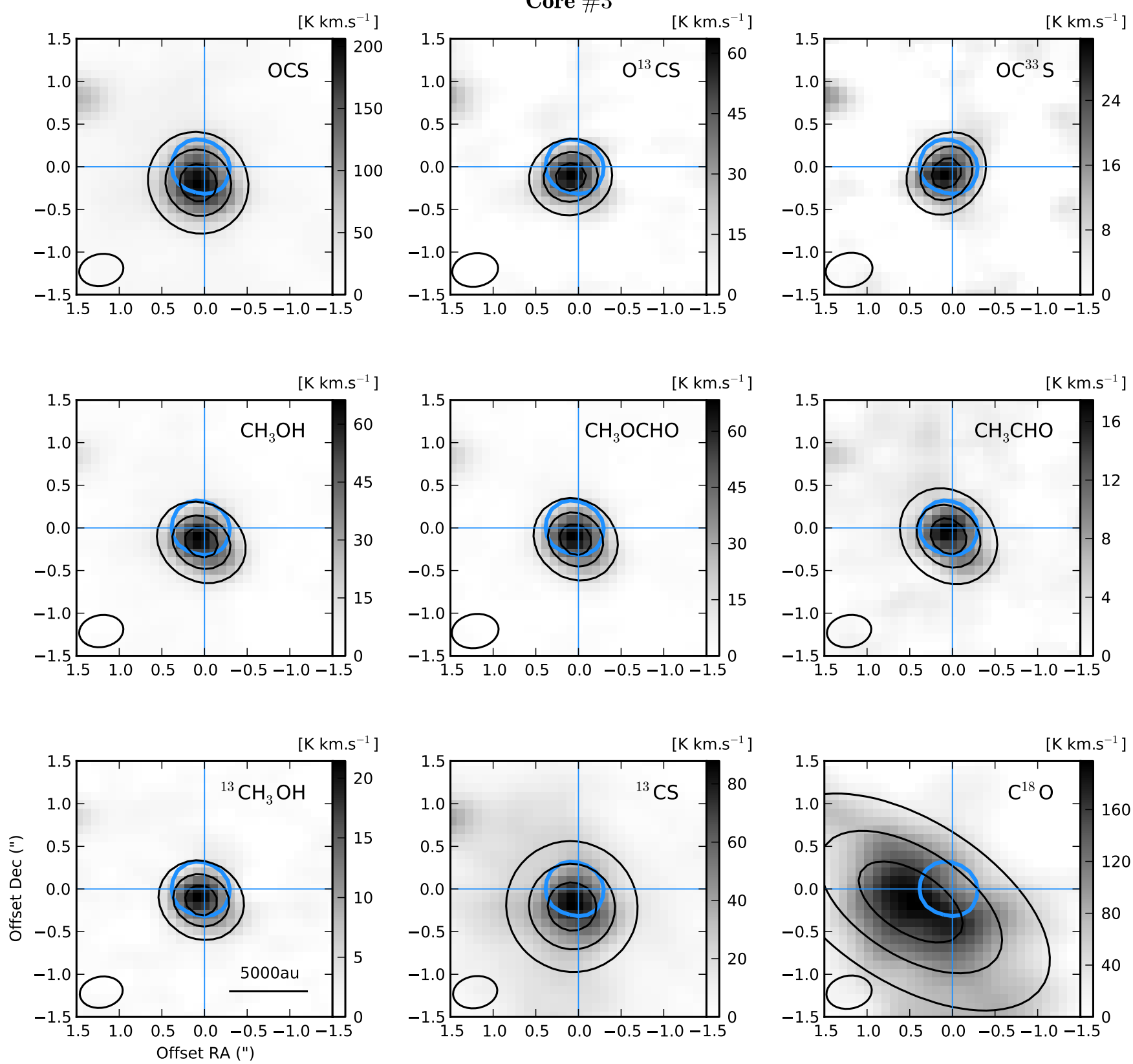

Fig. 4. Velocity integrated intensity map (grey scale) around core \#3 for the molecules centred on the continuum core. The velocity range chosen for the integration is $95-97 \mathrm{~km} \mathrm{~s}^{-1}$, which corresponds to the central emission peak. Temperature is the main beam brightness temperature $T_{\mathrm{mb}}$. The black contours represent the result of a Gaussian fit to the emission; the levels are 20, 50, and 80\% of the maximum. The maps are centred on the continuum core represented in blue contours (50\% of the maximum). The beam is represented on the bottom left corner of each map.

performed for these molecules. For the optically thick molecules, a correction of the column density is made with their observed isotopologues; the corrected values are in Table 5 for core \#3 and in Table 6 for core \#6. The $\mathrm{O}^{13} \mathrm{CS} / \mathrm{OC}^{33} \mathrm{~S}$ ratio for core \#6 and the $\mathrm{O}^{13} \mathrm{CS} / \mathrm{OC}^{33} \mathrm{~S}$ and ${ }^{13} \mathrm{CH}_{3} \mathrm{OH} / \mathrm{CH}_{3}^{18} \mathrm{OH}$ ratios for core \#3 are consistent with the elemental isotopic ratios mentioned in Sect. 3.2.

The obtained abundances relative to $\mathrm{H}_{2}$ are displayed in Fig. 6. We consider that the depth of the molecular distribution along the line of sight is equal to the size of the continuum cores, hence we use column density values $N_{\mathrm{H} 2}=(2.6 \pm 0.1) \times$ $10^{25} \mathrm{~cm}^{-2}$ and $N_{\mathrm{H} 2}=(1.9 \pm 0.3) \times 10^{25} \mathrm{~cm}^{-2}$ (for core \#3 and \#6, respectively) from $n_{\mathrm{H}_{2}}$ densities in Table 2 for a source size equal to the size of the beam. Only the molecules centred on the cores are selected because they are more likely to be directly associated to the core. We chose to take all the abundances derived at the mean temperature $T_{\mathrm{ex}}=190 \mathrm{~K}$ for core \#3. To investigate the nature of core \#6, we have derived the abundances in the typical range of temperature for star-forming regions $\left(T_{\mathrm{ex}}=10-200 \mathrm{~K}\right)$. The values observed for various starforming regions (see Table 4) are plotted for comparison and the nature of the cores are discussed in the next section.

\section{Discussion}

When considering the distribution of the molecules around core \#6, the high density component observed at the north-east of core \#6 may be associated to the heating of the outer envelope of the core by the interaction with a shock. Core \#6 appears to be in a large-scale shock, traced by the $\mathrm{SiO}$ distribution in Fig. 2, and 

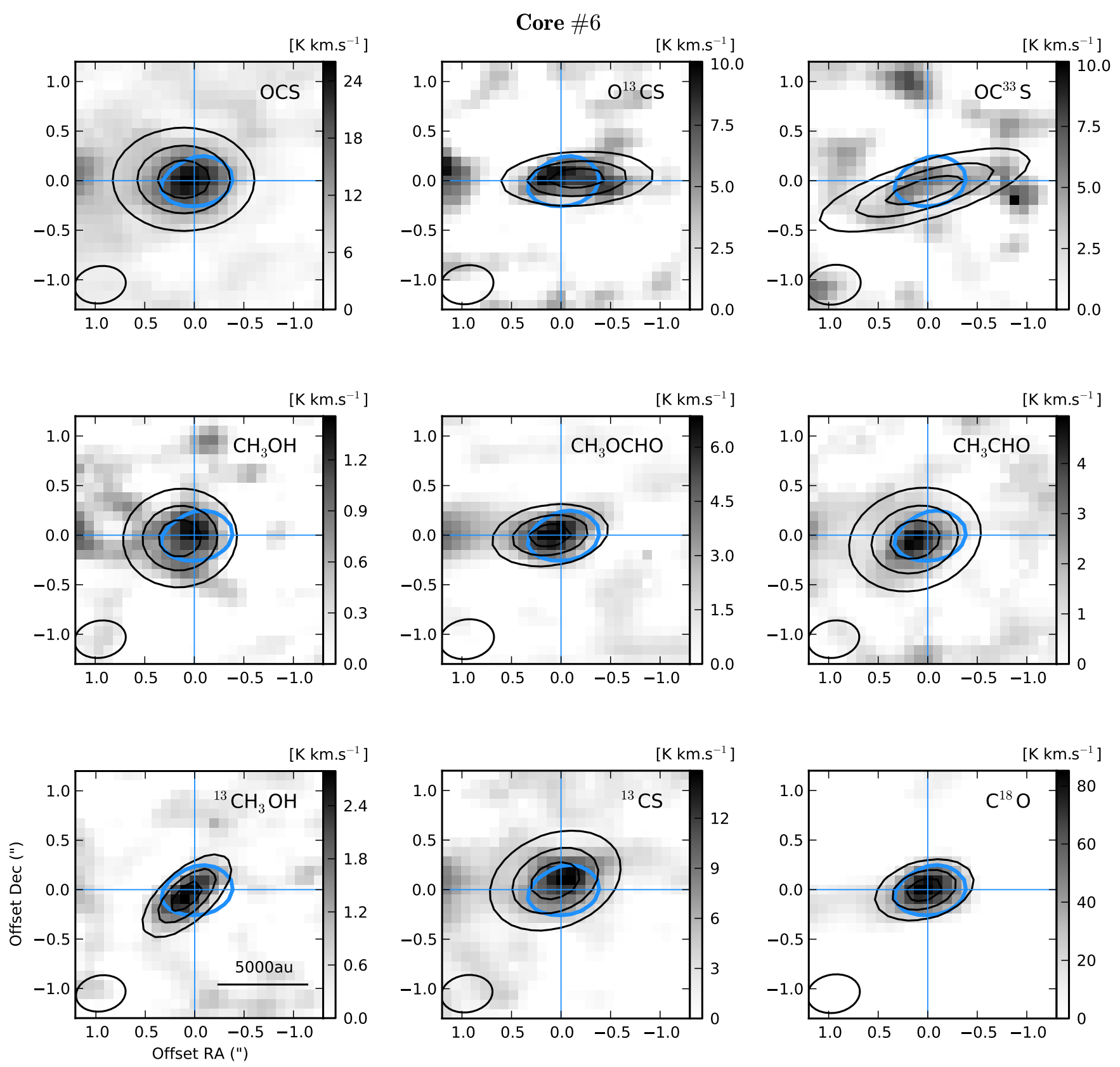

Fig. 5. Same as Fig. 4 but for core \#6.

Louvet et al. (2016) showed that the narrow component of the $\mathrm{SiO}$ emission comes from the low-velocity shock spread along the length of the ridge. We note also that Nony et al. (2018) showed that an outflow seen in $\mathrm{SiO}$ and $\mathrm{CO}$ emission comes from core \#18 in this direction.

The lines detected towards core \#6 are narrower than towards core \#3, with a mean line width of $3.2 \pm 0.1 \mathrm{~km} \mathrm{~s}^{-1}$ against $5.2 \pm 0.2 \mathrm{~km} \mathrm{~s}^{-1}$. Narrower lines for core \#6 are a first clue to propose that it is less active and thus less evolved than its protostellar neighbour. The difference in state of evolution cannot be due to the W-R/OB stars association of W43, which is located $\sim 5 \mathrm{pc}$ away, as the cores are out of the ionisation front caused by their UV radiation (Motte et al. 2003; Nguyen-Luong et al. 2017). Furthermore the cores do not show any inner velocity gradient at the spatial and spectral resolutions of our observations.

The COMs detected in core \#6 are usually detected in hot cores, where they are formed on grain mantles and then desorbed during the warm-up phase. However, the detection of these molecules in low-mass prestellar cores (Bacmann et al. 2012; Cernicharo et al. 2012; Vastel et al. 2014) shows that their presence is not sufficient to determine the nature of the core. Also, lower abundances of COMs in this core with respect to core \#3 is not a direct proof of a prestellar signature since other sources, like warm carbon chain chemistry sources, are poor in COMs (Sakai et al. 2008).

Hereafter we compare the abundances observed in core \#3 and \#6 to those in other sources considering two scenarios. In the first one, the size of the region emitting the detected molecules is taken as equal to the beam; in the second one, we consider that they are unresolved. The abundances taken in the literature for the other sources correspond to different source sizes and are not corrected by the filling factor or the $\mathrm{H}_{2}$ column density. Nonetheless the trends remain the same: the molecules are more abundant in the high-mass hot cores than in hot corinos and even 
Table 4. Sources used for comparison with cores \#3 and \#6.

\begin{tabular}{|c|c|c|c|c|c|c|c|c|}
\hline Source & $\begin{array}{c}\text { Name } \\
\text { in Fig. } 6\end{array}$ & $\begin{array}{l}\text { Nature of } \\
\text { the core }\end{array}$ & $\begin{array}{c}\text { Hot core/ } \\
\text { corino }\end{array}$ & $\begin{array}{c}\text { Distance } \\
(\mathrm{kpc})\end{array}$ & $\begin{array}{l}\text { Size } \\
(\mathrm{au})\end{array}$ & Mass & $\begin{array}{l}L_{\text {bol }} \\
\left(L_{\odot}\right)\end{array}$ & Reference \\
\hline L134N & L134N & Prestellar & - & 0.2 & 1500 & LM & $10^{-2}$ & Ohishi et al. (1992) \\
\hline B1b-S & B1b-S & Young protostar & Hot corino & 0.2 & 80 & $\mathrm{LM}$ & $10^{-1}$ & Marcelino et al. (2018) \\
\hline B1b-N & B1b-N & FHSC candidate & - & 0.2 & 500 & LM & $10^{-1}$ & Gerin et al. (2015) \\
\hline L1544 & L1544 & Prestellar & - & 0.1 & $>4000$ & LM & $10^{0}$ & Vastel et al. $(2014,2018)$ \\
\hline L1689B & L1689B & Prestellar & - & 0.1 & 3500 & LM & $10^{0}$ & Bacmann et al. (2012) \\
\hline NGC 1333 IRAS 4 A2 & IRAS 4A2 & Protostellar & Hot corino & 0.2 & 250 & LM & $10^{1}$ & López-Sepulcre et al. (2017) \\
\hline IRAS $16293-2442$ & IRAS 16293 & Protostellar & Hot corino & 0.1 & 150 & LM & $10^{1}$ & Cazaux et al. (2003) \\
\hline W43-MM1 \#6 & Core 6 & Prestellar? & $?$ & 5.5 & 1300 & $\mathrm{HM}$ & $10^{1}$ & Nony et al. (2018) \\
\hline CepE-A & CepE-A & Protostellar & Hot corino & 0.7 & 510 & $\mathrm{IM}$ & $10^{2}$ & Ospina-Zamudio et al. (2018) \\
\hline NGC 7129 FIRS2 & FIRS2 & Protostellar & Hot core & 1.2 & 1900 & IM & $10^{2}$ & Fuente et al. (2014) \\
\hline NGC 2264 CMM3A & CMM3A & Protostellar & Hot core & 0.7 & 200 & $\mathrm{IM}$ & $10^{2}$ & Watanabe et al. (2017) \\
\hline NGC 7538S MM3 & MM3 & Prestellar? & ? & & 1100 & IM & & \\
\hline MM2 & MM2 & Protostellar & Hot core & 2.6 & 1100 & IM & $10^{4(a)}$ & Feng et al. (2016) \\
\hline MM1 & MM1 & Protostellar & Hot core & & 1100 & $\mathrm{HM}$ & & \\
\hline $\begin{array}{l}\text { CygX-N63 hot core } \\
\text { lukewarm region }\end{array}$ & $\begin{array}{l}\text { N63hc } \\
\text { N63lw }\end{array}$ & Young protostar & Hot core & 1.4 & $\begin{array}{c}500 \\
2100\end{array}$ & $\begin{array}{l}\mathrm{HM} \\
\mathrm{HM}\end{array}$ & $10^{2(a)}$ & Fechtenbaum (2015) \\
\hline W43-MM1 \#3 & Core 3 & Protostellar & Hot & 5. & 1200 & $\mathrm{HM}$ & $10^{3}$ & Nony et al. ( \\
\hline G35.20-0.74N A & G35.20 & Protostellar & Hot core & 2.2 & 1300 & $\mathrm{HM}$ & $10^{4}$ & Allen et al. (2017) \\
\hline $\mathrm{G} 35.03+0.35 \mathrm{~A}$ & G35.03 & Protostellar & Hot core & 2.3 & 1100 & $\mathrm{HM}$ & $10^{4}$ & Allen et al. (2017) \\
\hline $\mathrm{G} 34.26+015$ & G34.26 & Protostellar & Hot core & 3.7 & 3500 & $\mathrm{HM}$ & $10^{4}$ & Mookerjea et al. (2007) \\
\hline Orion KL & KL & Protostellar & Hot core & 0.4 & 4000 & $\mathrm{HM}$ & $10^{5}$ & $\begin{array}{l}\text { Sutton et al. (1995) } \\
\text { Crockett et al. (2014) }\end{array}$ \\
\hline Sgr B2(N2) & SgrB2 & Protostellar & Hot core & 8.3 & 12000 & $\mathrm{HM}$ & $10^{6}$ & Belloche et al. (2016) \\
\hline
\end{tabular}

Notes. The distance is from the Sun. LM, IM, and HM stand for low-mass $\left(M<2 M_{\odot}\right)$, intermediate-mass $\left(2 M_{\odot}<M<8 M_{\odot}\right)$, and high-mass $\left(M>8 M_{\odot}\right)$, respectively. The third column indicates if the protostellar cores harbour a hot core or a hot corino. ${ }^{\left({ }^{(}\right)}$Total value from all the sources mentioned.

Table 5. Column densities in core \#3 estimated from isotopologues.

\begin{tabular}{lc}
\hline \hline Molecule & $N\left(\mathrm{~cm}^{-2}\right)$ \\
\hline $\mathrm{CH}_{3} \mathrm{OH}$ & $5.1 \pm 2.7(18)$ \\
$\mathrm{CS}$ & $4.0 \pm 1.2(16)$ \\
$\mathrm{OCS}$ & $1.4 \pm 0.5(17)$ \\
$\mathrm{H}_{2} \mathrm{CO}$ & $9.4 \pm 2.7(16)$ \\
$\mathrm{CO}$ & $>5.3(19)$ \\
\hline
\end{tabular}

Notes. $a(b)=a \times 10^{b}$. The methanol density is derived from the rotational diagrams of its isopotologues. For the other molecules, the densities are obtained using isotopologue column densities at $190 \mathrm{~K}$. The source size is assumed to be equal to the beam.

more than in low-mass prestellar cores. Thus it does not impact the qualitative discussion that follows.

\subsection{Cores sizes similar to the beam}

In this case, we consider no beam dilution. The observed abundances towards core \#3 are represented in Fig. 6 by red filled squares and those towards core \#6 by blue solid lines. First of all, the observed abundances are globally lower than for the other sources. Indeed we find column densities of the same order as for other sources but the local densities $\left(\sim 7 \times 10^{9} \mathrm{~cm}^{-3}\right)$ are huge compared to the usual $n_{\mathrm{H}_{2}} \sim 10^{5}-10^{8} \mathrm{~cm}^{-3}$ observed in star-forming regions. Core \#3 abundances are at least an order of magnitude below for OCS and $\mathrm{CH}_{3} \mathrm{OCHO}$ compared to the other high-mass protostellar cores. However, for $\mathrm{CH}_{3} \mathrm{OH}$ and
$\mathrm{CH}_{3} \mathrm{OCH}_{3}$, the core $\# 3$ results are more consistent with some hot cores (G35.20-0.74N A and G35.03+0.35 A). All abundances derived for core \#6 are much lower than other sources at hot core and hot corino temperatures, except the $\mathrm{CH}_{3} \mathrm{OH}$ value compatible with NGC 2264 CMM3A.

The only sources comparable are cold low-mass prestellar cores (L1544, L1689B) and the very young low-mass protostar B1b-N, suggesting a temperature of about $20 \mathrm{~K}$. The envelope on a 2400 au scale would be at the same temperature as the dust, whose temperature is around $23 \mathrm{~K}$. This means that there is no internal source of heating (in other terms a protostar), since such a source would unbalance the two temperatures. At this low temperature, bright emission of the $J=3-2$ line of $\mathrm{N}_{2} \mathrm{D}+$ $\left(v=231.32183 \mathrm{GHz}, E_{\text {up }}=22.2 \mathrm{~K}\right)$ could be expected (Tobin et al. 2019) but it is not detected, suggesting that the core is hotter than estimated in this scenario.

\subsection{Unresolved cores}

We suppose now that the size of the molecular emission is smaller than the beam size. The molecular column densities are corrected by the filling factor assuming a $r^{-2}$ density model for $n_{\mathrm{H}_{2}}$. When considering core sizes smaller than $500 \mathrm{au}$, all lines become optically thick in our temperature range and their profiles no longer match with our observations. With a core size of $500 \mathrm{au}, n_{\mathrm{H}_{2}}=1.5 \times 10^{10} \mathrm{~cm}^{-3}\left(N_{\mathrm{H}_{2}}=9.0 \times 10^{24} \mathrm{~cm}^{-2}\right)$ and $n_{\mathrm{H}_{2}}=1.3 \times 10^{10} \mathrm{~cm}^{-3}\left(N_{\mathrm{H}_{2}}=7.0 \times 10^{24} \mathrm{~cm}^{-2}\right)$ for cores \#3 and \#6, respectively. The abundances are thus enhanced by a factor of 12 with a source size of 500 au compared to a source size of $2400 \mathrm{au}$. It is also a way to mimic results from a source with the size of 


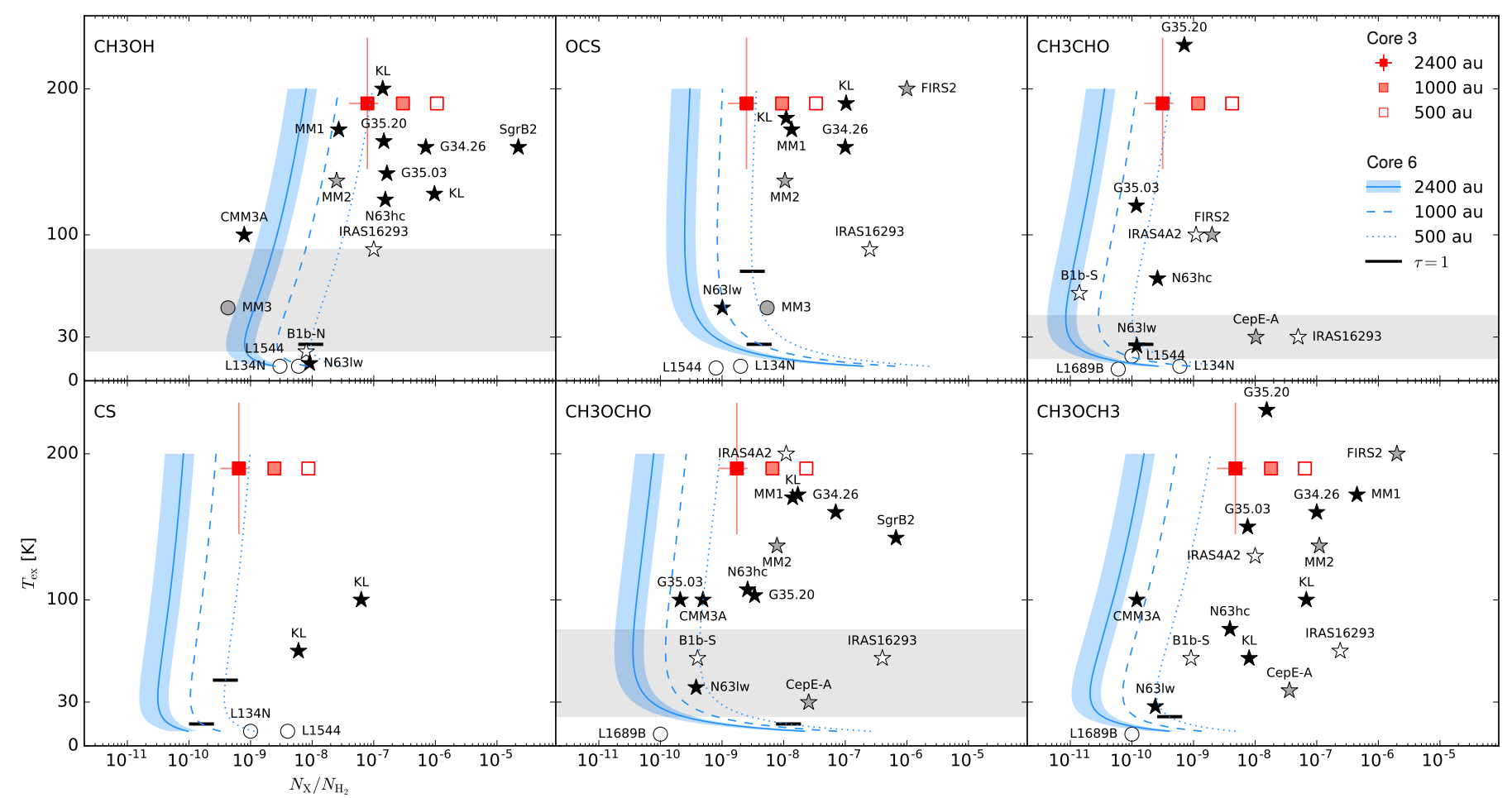

Fig. 6. Abundances with respect to $\mathrm{H}_{2}$ for selected molecules. Results for core \#3 (red squares) and core \#6 (blue lines) considering different source sizes (see legend) are from LTE modelling. The temperature $T_{\mathrm{ex}}=190 \mathrm{~K}$ is fixed for core \#3, it varies from 10 to $200 \mathrm{~K}$ for core \#6. The blue area represents an error of 50\% on the estimation of the abundance, which includes the error on the line area and on the value of $N_{\mathrm{H}_{2}}$. The grey area is the temperature range estimated for core \#6 from the rotational diagrams. For a given size, a molecule becomes optically thick below the black line. The sources listed in Table 4 are represented by a dot for prestellar cores or a star for protostellar cores. The colour code is white for low-mass, grey for intermediate-mass, and black for high-mass cores. The names refer to Col. 2 of Table 4.

Table 6. Column densities in core \#6 estimated for different scenarios.

\begin{tabular}{|c|c|c|c|c|}
\hline $\begin{array}{l}\text { Size } \\
T_{\mathrm{ex}} \\
\end{array}$ & $\begin{array}{c}2400 \mathrm{au} \\
20 \mathrm{~K}\end{array}$ & $\begin{array}{c}1000 \mathrm{au} \\
30 \mathrm{~K}\end{array}$ & $\begin{array}{c}1000 \mathrm{au} \\
80 \mathrm{~K}\end{array}$ & $\begin{array}{c}500 \mathrm{au} \\
80 \mathrm{~K} \\
\end{array}$ \\
\hline Molecule & \multicolumn{4}{|c|}{$N\left(\mathrm{~cm}^{-2}\right)$} \\
\hline $\mathrm{C}^{18} \mathrm{O}$ & $1.3(16)$ & $4.9(16)$ & $9.4(16)$ & $3.4(17)$ \\
\hline $\mathrm{CH}_{3} \mathrm{OH}$ & $2.9(17)$ & $1.4(17)$ & $3.0(16)$ & $1.1(17)$ \\
\hline${ }^{13} \mathrm{CH}_{3} \mathrm{OH}$ & $1.4(15)$ & $4.6(15)$ & 1.1(16) & $4.0(16)$ \\
\hline $\mathrm{CH}_{3} \mathrm{CHO}$ & $9.4(14)$ & $1.8(15)$ & $2.1(15)$ & $7.6(15)$ \\
\hline${ }^{13} \mathrm{CS}$ & $4.5(13)$ & $1.3(14)$ & $1.7(14)$ & $6.2(14)$ \\
\hline $\mathrm{CH}_{3} \mathrm{OCH}_{3}$ & $3.8(15)$ & $8.3(15)$ & $1.4(16)$ & $5.0(16)$ \\
\hline $\mathrm{CH}_{3} \mathrm{OCHO}$ & $1.3(16)$ & $1.4(16)$ & $7.0(15)$ & $2.5(16)$ \\
\hline OCS & $2.9(16)$ & $2.3(16)$ & $6.1(15)$ & $2.2(16)$ \\
\hline $\mathrm{O}^{13} \mathrm{CS}$ & $3.2(15)$ & $3.1(15)$ & $1.0(15)$ & $3.7(15)$ \\
\hline $\mathrm{OC}^{33} \mathrm{~S}$ & $1.8(15)$ & $1.7(15)$ & $5.9(14)$ & $2.1(15)$ \\
\hline
\end{tabular}

Column densities estimated from the isotopologues

\begin{tabular}{lllll}
$\mathrm{CH}_{3} \mathrm{OH}$ & $6.3(16)$ & $2.1(17)$ & $5.0(17)$ & $1.8(18)$ \\
$\mathrm{CS}$ & $1.9(15)$ & $5.9(15)$ & $7.7(15)$ & $2.8(16)$ \\
$\mathrm{OCS}$ & $1.5(17)$ & $1.5(17)$ & $4.9(16)$ & $1.8(17)$ \\
$\mathrm{CO}$ & $4.3(18)$ & $1.6(19)$ & $3.1(19)$ & $1.1(20)$ \\
\hline
\end{tabular}

Notes. $a(b)=a \times 10^{b}$.

the beam but with a local density of $\sim 10^{8} \mathrm{~cm}^{-3}$ compatible with young protostellar cores.

With a size of $500 \mathrm{au}$, results from core \#3 are more consistent with high-mass protostellar cores for $\mathrm{OCS}$ and $\mathrm{CH}_{3} \mathrm{OCHO}$ (see red empty squares on Fig. 6). However, the brightest lines become optically thick. Considering a size of 1000 au for core \#3 (pale red filled squares on Fig. 6) seems a better compromise to match with the observed line profiles and the other core abundances at the same time. The corresponding column densities are listed in Table A.3.

For core \#6, with a size of 500 au (blue dotted lines on Fig. 6) the results are comparable to cores at various evolutionary stages between 20 and $90 \mathrm{~K}$. However, some of the main lines are optically thick (e.g. ${ }^{13} \mathrm{CS}$ and OCS) for temperatures lower than $75 \mathrm{~K}$ excluding the scenario of a compact cold core. This leaves the possibility of a compact core at a high temperature of $80 \mathrm{~K}$, included in the temperature range given by the rotational diagrams and consistent with sources like the hot corino B1b-S and the protostellar core NGC 2264 CMM3A. By adjusting the size of core \#6 to 1000 au (blue dashed lines on Fig. 6), most of the lines become optically thin and low temperatures are possible. In particular, the $\mathrm{CH}_{3} \mathrm{OH}$ and $\mathrm{CH}_{3} \mathrm{CHO}$ abundances match with L134N values at $20 \mathrm{~K}$ with a comparable size. The observed abundances for core \#6 with sizes 500-1000 au are also comparable to the lukewarm region of the young high-mass protostellar core CygX-N63 (2100 au, Fechtenbaum 2015), but still at least an order of magnitude below the 500 au N63 hot core values.

NGC $7538 \mathrm{~S}$ MM1 is a high-mass protostellar object, more evolved than the hot molecular core NGC 7538 S MM2 and NGC 7538 S MM3, which is comparable to prestellar objects because it only exhibits emission of lower excitation lines. While the core \#3 results match with NGC 7538 S MM1, core \#6 is more likely to be similar to NGC 7538 S MM3. Also, B1b-S displays a spectrum as rich in lines as core \#3, and the B1b-N molecular emission shown in Marcelino et al. (2018) is as poor as core \#6. However, the $\mathrm{CH}_{3} \mathrm{OH}$ emission in $\mathrm{B} 1 \mathrm{~b}-\mathrm{N}$ is associated to a 
nascent outflow of size 1300 au (Gerin et al. 2015), unresolved at our beam size, but with abundances comparable to core \#6.

\section{Conclusion}

The study of the molecular content of core \#6 is challenging because of the few and weakly observed lines. We have identified 17 molecules in core \#6 based on the analysis of its line-rich neighbour core \#3. The distribution of these molecules reveals that ten are directly associated to core \#6 and the others can be associated to the interaction between its envelope and the low-velocity shock of the ridge. The determination of the column densities and the temperatures from rotational diagrams was only possible for three molecules, methanol $\left(\mathrm{CH}_{3} \mathrm{OH}\right)$, methyl formate $\left(\mathrm{CH}_{3} \mathrm{OCHO}\right)$, and acetaldehyde $\left(\mathrm{CH}_{3} \mathrm{CHO}\right)$. Because of the low signal-to-noise ratio $(\mathrm{S} / \mathrm{N})$ and the range of upper energy levels, there is a huge uncertainty on the temperature (15-90 K) obtained by this method. To better constrain the temperature and core nature, we have compared our observations to the abundances of different sources including prestellar cores, hot corinos, and hot cores. The conclusion about the nature of core \#6 clearly depends on the estimated size of the core:

- at the size of the beam, $2400 \mathrm{au}$, the core is cold ( $\left.T_{\mathrm{ex}} \approx T_{\text {dust }}\right)$ and may be prestellar or in a transition phase to a protostellar core; however, the non detection of the $\mathrm{N}_{2} \mathrm{D}+$ emission suggests that the temperature is greater than $20 \mathrm{~K}$.

- if the core size is $1000 \mathrm{au}$, it could be at the very beginning of the protostellar phase at $20-30 \mathrm{~K}$ or a young protostellar core at $\sim 80 \mathrm{~K}$ not active enough to display large outflows;

- considering a size of $500 \mathrm{au}$, the core still cannot be comparable to hot cores but only to a hot corino with a temperature of $\sim 80 \mathrm{~K}$.

- the source size is not less than 500 au because the lines would be optically thick, which is not observed.

Core \#6 is not as evolved as core \#3, the absence of outflows in $\mathrm{CO}$ and $\mathrm{SiO}$ suggests that it does not contain a protostar. From the molecular study it appears as a good high-mass prestellar core candidate and deep dedicated line surveys with a higher spatial resolution are still necessary to investigate whether it harbours a hot corino, like those found towards low-mass class 0 protostars.

Acknowledgements. This paper makes use of the following ALMA data: ADS/JAO.ALMA\#2013.1.01365.S, ADS/JAO.ALMA\#2015.1.01273.S. ALMA is a partnership of ESO (representing its member states), NSF (USA), and NINS (Japan), together with NRC (Canada), MOST and ASIAA (Taiwan), and KASI (Republic of Korea), in cooperation with the Republic of Chile. The Joint ALMA Observatory is operated by ESO, auI/NRAO, and NAOJ. This work was supported by the Programme National de Physique Stellaire and Physique et Chimie du Milieu Interstellaire (PNPS and PCMI) of CNRS/INSU (with INC/INP/IN2P3).

\section{References}

Allen, V., van der Tak, F. F. S., Sánchez-Monge, Á., Cesaroni, R., \& Beltrán, M. T. 2017, A\&A, 603, A133

Bacmann, A., Taquet, V., Faure, A., Kahane, C., \& Ceccarelli, C. 2012, A\&A, 541, L12

Belloche, A., Müller, H. S. P., Garrod, R. T., \& Menten, K. M. 2016, A\&A, 587, A91

Bonnell, I. A., \& Bate, M. R. 2006, MNRAS, 370, 488
Bontemps, S., Motte, F., Csengeri, T., \& Schneider, N. 2010, A\&A, 524, A18 Braz, M. A., \& Epchtein, N. 1983, A\&AS, 54, 167

Cazaux, S., Tielens, A. G. G. M., Ceccarelli, C., et al. 2003, ApJ, 593, L51 Cernicharo, J., Marcelino, N., Roueff, E., et al. 2012, ApJ, 759, L43

Chin, Y.-N., Henkel, C., Whiteoak, J. B., Langer, N., \& Churchwell, E. B. 1996 A\&A, 305, 960

Crockett, N. R., Bergin, E. A., Neill, J. L., et al. 2014, ApJ, 787, 112

Cyganowski, C. J., Brogan, C. L., Hunter, T. R., et al. 2014, ApJ, 796, L2

Duarte-Cabral, A., Bontemps, S., Motte, F., et al. 2014, A\&A, 570, A1

Fechtenbaum, S. 2015, Ph.D. Thesis, University of Bordeaux, France

Feng, S., Beuther, H., Semenov, D., et al. 2016, A\&A, 593, A46

Fuente, A., Cernicharo, J., Caselli, P., et al. 2014, A\&A, 568, A65

Gerin, M., Pety, J., Fuente, A., et al. 2015, A\&A, 577, L2

Gerner, T., Beuther, H., Semenov, D., et al. 2014, A\&A, 563, A97

Grushka, E. 1972, Anal. Chem., 44, 1733

Herbst, E., \& van Dishoeck, E. F. 2009, ARA\&A, 47, 427

Jørgensen, J. K., van der Wiel, M. H. D., Coutens, A., et al. 2016, A\&A, 595, A117

Kong, S., Tan, J. C., Caselli, P., et al. 2017, ApJ, 834, 193

López-Sepulcre, A., Sakai, N., Neri, R., et al. 2017, A\&A, 606, A121

Louvet, F. 2018, in SF2A-2018: Proceedings of the Annual meeting of the French Society of Astronomy and Astrophysics, 311

Louvet, F., Motte, F., Hennebelle, P., et al. 2014, A\&A, 570, A15

Louvet, F., Motte, F., Gusdorf, A., et al. 2016, A\&A, 595, A122

Marcelino, N., Gerin, M., Cernicharo, J., et al. 2018, A\&A, 620, A80

McKee, C. F., \& Tan, J. C. 2003, ApJ, 585, 850

McMullin, J. P., Waters, B., Schiebel, D., Young, W., \& Golap, K. 2007, in Astronomical Data Analysis Software and Systems XVI, eds. R. A. Shaw, F. Hill, \& D. J. Bell, ASP Conf. Ser., 376, 127

Milam, S. N., Savage, C., Brewster, M. A., Ziurys, L. M., \& Wyckoff, S. 2005, ApJ, 634, 1126

Mookerjea, B., Casper, E., Mundy, L. G., \& Looney, L. W. 2007, ApJ, 659, 447

Motte, F., Schilke, P., \& Lis, D. C. 2003, ApJ, 582, 277

Motte, F., Bontemps, S., Schilke, P., et al. 2007, A\&A, 476, 1243

Motte, F., Bontemps, S., \& Louvet, F. 2018a, ARA\&A, 56, 41

Motte, F., Nony, T., Louvet, F., et al. 2018b, Nat. Astron., 2, 478

Nguyen Luong, Q., Motte, F., Hennemann, M., et al. 2011, A\&A, 535, A76

Nguyen-Luong, Q., Motte, F., Carlhoff, P., et al. 2013, ApJ, 775, 88

Nguyen-Luong, Q., Anderson, L. D., Motte, F., et al. 2017, ApJ, 844, L25

Nony, T., Louvet, F., Motte, F., et al. 2018, A\&A, 618, L5

Ohishi, M., Irvine, W. M., \& Kaifu, N. 1992, in Astrochemistry of Cosmic Phenomena, ed. P. D. Singh, IAU Symp., 150, 171

Ospina-Zamudio, J., Lefloch, B., Ceccarelli, C., et al. 2018, A\&A, 618, A145

Sakai, N., Sakai, T., Hirota, T., \& Yamamoto, S. 2008, ApJ, 672, 371

Sanchez-Monge, A., Schilke, P., Ginsburg, A., Cesaroni, R., \& Schmiedeke, A. 2017, Astrophysics Source Code Library [record ascl:1704.004]

Schöier, F. L., van der Tak, F. F. S., van Dishoeck, E. F., \& Black, J. H. 2005 A\&A, 432, 369

Smith, R. J., Longmore, S., \& Bonnell, I. 2009, MNRAS, 400, 1775

Sutton, E. C., Peng, R., Danchi, W. C., et al. 1995, ApJS, 97, 455

Tielens, A. G. G. M. 2005, The Physics and Chemistry of the Interstellar Medium (Cambridge: Cambridge University Press.)

Tigé, J., Motte, F., Russeil, D., et al. 2017, A\&A, 602, A77

Tobin, J. J., Bourke, T. L., Mader, S., et al. 2019, ApJ, 870, 81

Valdettaro, R., Palla, F., Brand, J., et al. 2001, A\&A, 368, 845

Vastel, C., Ceccarelli, C., Lefloch, B., \& Bachiller, R. 2014, ApJ, 795, L2

Vastel, C., Bottinelli, S., Caux, E., Glorian, J.-M., \& Boiziot, M. 2015, in SF2A2015: Proceedings of the Annual meeting of the French Society of Astronomy and Astrophysics, eds. F. Martins, S. Boissier, V. Buat, L. Cambrésy, \& P. Petit, 313

Vastel, C., Quénard, D., Le Gal, R., et al. 2018, MNRAS, 478, 5514

Vázquez-Semadeni, E., González-Samaniego, A., \& Colín, P. 2017, MNRAS, 467,1313

Walsh, A. J., Burton, M. G., Hyland, A. R., \& Robinson, G. 1998, MNRAS, 301, 640

Wang, K., Zhang, Q., Testi, L., et al. 2014, MNRAS, 439, 3275

Watanabe, Y., Sakai, N., López-Sepulcre, A., et al. 2017, ApJ, 847, 108

Wilson, T. L., \& Rood, R. 1994, ARA\&A, 32, 191

Wolfire, M. G., \& Cassinelli, J. P. 1987, ApJ, 319, 850

Wu, B., Tan, J. C., Christie, D., et al. 2017, ApJ, 841, 88

Zhang, B., Moscadelli, L., Sato, M., et al. 2014, ApJ, 781, 89 
Appendix A: Additional material

Table A.1. Spectroscopic parameters of the transitions detected towards core \#3 and observed line parameters.

\begin{tabular}{|c|c|c|c|c|c|c|c|c|c|c|}
\hline $\begin{array}{c}\text { Frequency } \\
(\mathrm{MHz})\end{array}$ & Molecule & $\begin{array}{c}\text { Transition } \\
J=\end{array}$ & $\begin{array}{l}E_{\text {up }} \\
(\mathrm{K})\end{array}$ & $\begin{array}{l}S \mu^{2} \\
\left(\mathrm{D}^{2}\right)\end{array}$ & $\begin{array}{c}\log \left(A_{\mathrm{ij}}\right) \\
\left(\mathrm{s}^{-1}\right)\end{array}$ & $\begin{array}{c}n_{\text {crit }} \\
\left(\mathrm{cm}^{-3}\right)\end{array}$ & Database & $\begin{array}{l}\text { Line width } \\
\left(\mathrm{km} \mathrm{s}^{-1}\right)\end{array}$ & $\begin{array}{l}\text { Velocity } \\
\left(\mathrm{km} \mathrm{s}^{-1}\right)\end{array}$ & $\underset{\left(\mathrm{K} \mathrm{km} \mathrm{s}^{-1}\right)}{\int T_{\mathrm{mb}} \mathrm{d} v}$ \\
\hline 216109.78 & $\mathrm{CH}_{3} \mathrm{OCHO}$ & $19_{2,18}-18_{2,17} \mathrm{E}$ & 109.3 & 49.4 & -3.83 & - & JPL & $3.9 \pm 0.1$ & $97.2 \pm 0.1$ & $33.6 \pm 1.2$ \\
\hline 216115.57 & $\mathrm{CH}_{3} \mathrm{OCHO}$ & $19_{2,18}-18_{2,17} \mathrm{~A}$ & 109.3 & 49.4 & -3.83 & - & JPL & & 97.3 & 41.3 \\
\hline 216147.36 & $\mathrm{OC}^{33} \mathrm{~S}$ & $18-17$ & 98.6 & 9.2 & -4.04 & $1.3(6)^{(a)}$ & CDMS & & 96.6 & 8.0 \\
\hline 216210.91 & $\mathrm{CH}_{3} \mathrm{OCHO}$ & $19_{1,18}-18_{1,17} \mathrm{E}$ & 109.3 & 49.4 & -3.83 & - & JPL & & & $37.4 \pm 1.4$ \\
\hline 216216.54 & $\mathrm{CH}_{3} \mathrm{OCHO}$ & $19_{1,18}-18_{1,17} \mathrm{~A}$ & 109.3 & 49.4 & -3.83 & - & JPL & $5.1 \pm 0.2$ & $97.4 \pm 0.1$ & $40.4 \pm 2.8$ \\
\hline 217044.62 & ${ }^{13} \mathrm{CH}_{3} \mathrm{OH}$ & $14_{1,13}-13_{2,12}-$ & 254.3 & 5.8 & -4.62 & $1.2(7)^{(a)}$ & CDMS & 3.1 & 97.6 & $15.8 \pm 2.1$ \\
\hline 2171 & $\mathrm{SiO} v=0$ & $5-4$ & 31.3 & 48.0 & -3.28 & $4.8(6)$ & & & 91. & $>86$ \\
\hline 2171 & $\mathrm{CH}_{3} \mathrm{OCH}_{3}$ & $22_{4,19}-22_{3,20}$ & 253.4 & 327.7 & -4.27 & - & CDMS & $6.5 \pm 0.2$ & $96.9 \pm 0.1$ & $42.9 \pm 2.0$ \\
\hline 217238.54 & $\mathrm{DCN}$ & $3-2$ & 20.9 & 80.5 & -3.34 & - & CDMS & $5.8 \pm 0.3$ & $96.8 \pm 0.1$ & $51.4 \pm 4.5$ \\
\hline 218127.21 & $\mathrm{CH}_{3} \mathrm{COCH}_{3}$ & $20_{2,18}-19_{3,17} \mathrm{EE}$ & 119.1 & 1200.4 & -3.66 & - & JPL & $5.6 \pm 0.2$ & $97.0 \pm 0.1$ & $16.1 \pm 1.2$ \\
\hline 2181 & $\mathrm{O}^{13} \mathrm{CS}$ & $18-17$ & 99.5 & 9.2 & -4.52 & $4.1(5)^{(a)}$ & CDMS & $4.0 \pm 0.1$ & 97.1 & $19.1 \pm 0.9$ \\
\hline 2182 & $\mathrm{H}_{2} \mathrm{CO}$ & $3_{0,3}-2_{0,2}$ & 21.0 & 16.3 & -3.55 & $2.6(6)$ & CDMS & & & $>52$ \\
\hline 2182 & $\mathrm{CH}_{3} \mathrm{OCHO}$ & $17_{3,14}-16_{3,13} \mathrm{E}$ & 99.7 & 43.6 & -3.82 & - & JPL & 4.2 & 97.2 & 34.5 \\
\hline 2182 & $\mathrm{CH}_{3} \mathrm{OCHO}$ & $17_{3,14}-16_{3,13} \mathrm{~A}$ & 99.7 & 43.6 & -3.82 & - & JPL & & 97.1 & 32.9 \\
\hline 218324.72 & $\mathrm{HC}_{3} \mathrm{~N}$ & $24-23$ & 131.0 & 334.2 & -3.08 & $1.7(7)$ & CDMS & 5.3 & $96.6 \pm 0.1$ & $73.0 \pm 2.0$ \\
\hline 219505.59 & $\mathrm{C}_{2} \mathrm{H}_{5} \mathrm{CN}$ & $24_{2,22}-23_{2,21}$ & 135.6 & 353.2 & -3.05 & - & JP & 4.7 & 96.9 & 36.0 \\
\hline 219560.35 & $\mathrm{C}^{18} \mathrm{O}$ & $2-1$ & 15.8 & 0.02 & -6.22 & $9.9(3)^{(a)}$ & CDMS & & 96. & $>37$ \\
\hline 219908.53 & $\mathrm{H}_{2}{ }^{13} \mathrm{CO}$ & $3_{1,2}-2_{1}$ & 32.9 & 43.5 & -3.59 & $2.3(6)^{(a)}$ & CDMS & 4.6 & 97.2 & $35.7 \pm 2.5$ \\
\hline .44 & SO & $6_{5}-5_{4}$ & 35.0 & 14.0 & -3.87 & $2.3(6)$ & $\mathrm{CD}$ & & 97. & 56.0 \\
\hline .68 & $\mathrm{CH}_{3} \mathrm{OH}$ & $25_{3}-24_{4} \mathrm{E} 1$ & 802.2 & 8.4 & -4.70 & - & JPL & & 97.3 & 18.4 \\
\hline 219993.66 & $\mathrm{CH}_{3} \mathrm{OH}$ & $23_{5}-22_{6} \mathrm{E} 1$ & 775.9 & 6.6 & -4.76 & - & JPL & & 97.6 & $16.9 \pm 1.8$ \\
\hline 30315.79 & $\mathrm{CHO}$ & $12_{2,11}-11_{2}$ & 81.1 & 147.4 & -3.38 & - & $\mathrm{Jl}$ & 5.8 & 95.6 & $36.5 \pm 2.6$ \\
\hline .76 & $\mathrm{OH}$ & $22_{4}-21_{5} \mathrm{E} 1$ & 682.8 & 6.6 & -4.68 & - & JP & 5.0 & 97 & 30.2 \\
\hline .94 & $\mathrm{C}_{2} \mathrm{H}_{3} \mathrm{CN}$ & $24_{1}-23_{1}$ & 141.2 & 1045.0 & -2.50 & - & CDMS & 8.0 & 96.2 & 20.4 \\
\hline .00 & & $2-1$ & 16.6 & 0.02 & -6.16 & $1(4$ & CDMS & & 89. & $>550^{(b)}$ \\
\hline .55 & $\mathrm{C}_{2} \mathrm{H}_{5} \mathrm{OH}$ & $13_{2,11}-12_{2,10}$ & 138.6 & 20.3 & -3.97 & - & JP & 4.5 & 97.1 & 12.4 \\
\hline 230738.56 & $\mathrm{C}_{2} \mathrm{H}_{3} \mathrm{CN}$ & $25_{0}-24_{0}$ & 145.5 & 1089.8 & -2.53 & - & CDMS & $4.9 \pm 0.4$ & $96.2 \pm 0.3$ & $16.9 \pm 4.3$ \\
\hline 31060.99 & OCS & $19-18$ & 110.9 & 9.7 & -4.45 & $4.9(5)$ & MS & 57 & 065 & $129.2 \pm 3.5$ \\
\hline 0.68 & ${ }^{13} \mathrm{CS}$ & $5-4$ & 33.3 & 38.3 & -3.60 & $4.3(6)^{(a)}$ & & & & 78.9 \\
\hline 231269.90 & $\mathrm{CH}_{3} \mathrm{CHO}$ & $12_{6,7}-11_{6,6} \mathrm{E}$ & 153.4 & 113.9 & -3.48 & - & & & & 15.4 \\
\hline 231281.11 & $\mathrm{CH}_{3} \mathrm{OH}$ & $10_{2}-9_{3}-$ & 165.3 & 2.68 & -4.73 & $2.5(7)$ & JPL & $5.4 \pm 0.1$ & $97.2 \pm 0.1$ & $74.5 \pm 2.1$ \\
\hline 231310.42 & $\mathrm{C}_{2} \mathrm{H}_{5} \mathrm{CN}$ & $26_{1,25}-25_{1,24}$ & 153.4 & 383.1 & -2.98 & - & JPL & $4.9 \pm 0.1$ & $96.7 \pm 0.1$ & $48.0 \pm 1.5$ \\
\hline 231467.50 & $\mathrm{CH}_{3} \mathrm{CHO}$ & $12_{4,8}-11_{4,7} \mathrm{E}$ & 108.4 & 135.0 & -3.41 & - & JPL & $5.3 \pm 0.3$ & $96.2 \pm 0.1$ & 11.6 \\
\hline 231506.29 & $\mathrm{CH}_{3} \mathrm{CHO}$ & $12_{4,9}-11_{4,8} E$ & 108.2 & 135.0 & -3.41 & - & JPL & $6.0 \pm 0.6$ & $97.3 \pm 0.2$ & $17.2 \pm 2.7$ \\
\hline 31595.27 & $\mathrm{CH}_{3}$ & $12_{3,10}-11_{3,9} \mathrm{E}$ & 92.6 & 142.3 & -3.39 & - & $\mathrm{J}$ & 7.0 & 5.7 & $9.8 \pm 2.3$ \\
\hline 6.68 & $\mathrm{CH}_{3}^{18} \mathrm{OH}$ & $5_{-0,5}-4_{-0,4} E$ & 46.2 & 16.2 & -4.27 & $4.5(5)^{(a)}$ & CDMS & & & \\
\hline 231724.16 & $\mathrm{CH}_{3} \mathrm{OCHO}$ & $18_{4,14}-17_{4,13} \mathrm{E}$ & 300.8 & 45.8 & -3.75 & - & JPL & $4.0 \pm 0.3$ & $97.3 \pm 0.1$ & $7.6 \pm 1.0$ \\
\hline 231735.83 & $\mathrm{CH}_{3}^{18} \mathrm{OH}$ & $5-1,5-4_{-1,4} \mathrm{E}$ & 39.0 & 15.6 & -4.29 & $5.8(5)^{(a)}$ & CDMS & $5.2 \pm 0.3$ & $96.5 \pm 0.1$ & $11.6 \pm 1.2$ \\
\hline 231748.72 & $\mathrm{CH}_{3} \mathrm{CHO}$ & $12_{3,10}-11_{3,9} \mathrm{E}$ & 92.5 & 141.1 & -3.39 & - & JPL & $5.7 \pm 0.2$ & $96.5 \pm 0.1$ & $12.3 \pm 0.9$ \\
\hline 231758.45 & $\mathrm{CH}_{3}^{18} \mathrm{OH}$ & $5_{0,5}-4_{0,4} \mathrm{~A}$ & 33.4 & 16.2 & -4.27 & $4.5(5)^{(a)}$ & CDMS & $4.7 \pm 0.3$ & $97.1 \pm 0.1$ & $9.0 \pm 1.1$ \\
\hline 231796.52 & $\mathrm{CH}_{3}^{18} \mathrm{OH}$ & $5_{3,2}-4_{3,1} \mathrm{~A}$ & 83.5 & 10.3 & -4.47 & $4.2(5)^{(a)}$ & CDMS & $5.4 \pm 1.4$ & $97.8 \pm 0.4$ & $8.6 \pm 3.4$ \\
\hline 231801.47 & $\mathrm{CH}_{3}^{18} \mathrm{OH}$ & $5_{2,4}-4,3 \mathrm{~A}$ & 70.8 & 13.8 & -4.34 & $5.4(5)^{(a)}$ & CDMS & $4.2 \pm 0.5$ & $96.8 \pm 0.1$ & $8.0 \pm 1.4$ \\
\hline 231826.74 & $\mathrm{CH}_{3}^{18} \mathrm{OH}$ & $5_{1,4}-4_{1,3} E$ & 54.1 & 16.2 & -4.27 & $5.6(5)^{(a)}$ & CDMS & $4.5 \pm 0.5$ & $97.1 \pm 0.2$ & $6.7 \pm 1.2$ \\
\hline 231840.93 & $\mathrm{CH}_{3}^{18} \mathrm{OH}$ & $5_{2,3}-4_{2,2} \mathrm{~A}$ & 70.9 & 13.8 & -4.34 & $5.4(5)^{(a)}$ & CDMS & 4.2 & 97.4 & 6.3 \\
\hline 231847.58 & $\mathrm{CH}_{3} \mathrm{CHO}$ & $12_{3,9}-11_{3,8} \mathrm{E}$ & 92.6 & 141.2 & -3.39 & - & JPL & $6.2 \pm 0.8$ & $97.1 \pm 0.2$ & $13.3 \pm 2.7$ \\
\hline 231864.50 & $\mathrm{CH}_{3}^{18} \mathrm{OH}$ & $5_{2,3}-4_{2,2} E$ & 55.8 & 13.4 & -4.36 & $5.2(5)^{(a)}$ & CDMS & $4.0 \pm 0.2$ & $97.3 \pm 0.1$ & $6.0 \pm 0.7$ \\
\hline 231896.06 & $\mathrm{CH}_{3} \mathrm{OCHO}$ & $19_{4,16}-18_{4,15} \mathrm{E}$ & 309.7 & 48.14 & -3.75 & - & JPL & & $97.2=$ & $8.5 \pm 0.7$ \\
\hline 231903.90 & $\mathrm{CH}_{3} \mathrm{OCHO}$ & $19_{12,7}-18_{12,6} \mathrm{~A}$ & 395.1 & 30.46 & -3.95 & - & JPL & & $97.5 \pm$ & $8.2 \pm 1.1$ \\
\hline 231968.39 & $\mathrm{CH}_{3} \mathrm{CHO}$ & $12_{3,9}-11_{3,8} \mathrm{~A}$ & 92.6 & 142.3 & -3.38 & - & JPL & & & $12.1 \pm 1.3$ \\
\hline & $\mathrm{CH}_{3} \mathrm{OCH}_{3}$ & $13_{0,13}-12_{1,12}$ & 80.9 & 271.8 & -4.04 & - & CDMS & & & $57.1 \pm 4.7$ \\
\hline 63 & $\mathrm{C}_{2} \mathrm{H}_{5} \mathrm{OH}$ & $18_{5,14}-18_{4,15}$ & 175.3 & 18.6 & -4.13 & - & & & & $6.3 \pm 1.2$ \\
\hline 232160.19 & $\mathrm{CH}_{3} \mathrm{OCHO}$ & $199,10-18,9 \mathrm{E}$ & 353.3 & 39.3 & -3.83 & - & JPL & $4.7 \pm 0.9$ & $97.2 \pm$ & $9.6 \pm 2.8$ \\
\hline 232164.44 & $\mathrm{CH}_{3} \mathrm{OCHO}$ & $19_{10,10}-18_{10,9} \mathrm{~A}$ & 365.7 & 36.6 & -3.86 & - & JPL & & $97.5 \pm 0.3$ & $=3.0$ \\
\hline 232194.91 & ${ }^{13} \mathrm{CH}_{3} \mathrm{CN}$ & $13_{3}-12_{3}$ & 142.4 & 757.2 & -2.99 & $5.2(6)^{(a)}$ & JPL & $5.1 \pm 0.3$ & $97.1 \pm 0.1$ & $17.4 \pm 2.1$ \\
\hline
\end{tabular}

Notes. All observational values are integrated over the continuum core. ${ }^{(a)}$ Collision rate value from the main isotopologue. ${ }^{(b)}$ The line is selfabsorbed or filtered. The values correspond to the zero-base line width, the velocity of the line maximum, and the integration of the positive $T_{\mathrm{mb}}$ values.

A132, page 12 of 17 
Table A.1. continued.

\begin{tabular}{|c|c|c|c|c|c|c|c|c|c|c|}
\hline $\begin{array}{c}\text { Frequency } \\
(\mathrm{MHz})\end{array}$ & Mol & $\begin{array}{c}\text { Transition } \\
J=\end{array}$ & $\begin{array}{l}E_{\text {up }} \\
(\mathrm{K}) \\
\end{array}$ & $\begin{array}{l}S \mu^{2} \\
\left(\mathrm{D}^{2}\right) \\
\end{array}$ & $\begin{array}{c}\log \left(A_{\mathrm{ij}}\right) \\
\left(\mathrm{s}^{-1}\right)\end{array}$ & $\begin{array}{c}n_{\mathrm{crit}} \\
\left(\mathrm{cm}^{-3}\right)\end{array}$ & se & $\begin{array}{l}\text { Line width } \\
\left(\mathrm{km} \mathrm{s}^{-1}\right)\end{array}$ & $\begin{array}{l}\text { Velocity } \\
\left(\mathrm{km} \mathrm{s}^{-1}\right)\end{array}$ & $\begin{array}{c}\int T_{\mathrm{mb}} \mathrm{d} v \\
\left(\mathrm{~K} \mathrm{~km} \mathrm{~s}^{-1}\right)\end{array}$ \\
\hline 等 & $\mathrm{H}_{3} \mathrm{CN}$ & $13_{2}-12_{2}$ & & & -2.98 & $2(6)^{(a)}$ & - & .3 & $.2 \pm 0.2$ & 14.6 \\
\hline 9.8 & $\mathrm{CH}_{3} \mathrm{CN}$ & $13_{1}-$ & & & -2.97 & $2(6)^{(a)}$ & JPL & & & 13.9 \\
\hline 232234.19 & $\mathrm{CH}_{3} \mathrm{CN}$ & $13_{0}-12_{0}$ & 0 & 399.9 & -2.97 & $5.2(6)^{(a)}$ & JPL & & $7.1 \pm 0.2$ & $17.1 \pm 2.8$ \\
\hline & $\mathrm{HC}(\mathrm{O}) \mathrm{NH}_{2}$ & $11_{2,10}-10_{2,9}$ & 78.9 & 139.0 & -3.05 & - & CDMS & & $97.5 \pm 0.1$ & $13.2 \pm 1.1$ \\
\hline 32404.81 & $\mathrm{C}_{2} \mathrm{H}_{5} \mathrm{OH}$ & $17_{5,13}-17_{4,14}$ & 160.1 & 17.5 & -4.14 & - & JPL & $4.5 \pm 0.5$ & $97.0 \pm 0.2$ & $6.7 \pm 1.2$ \\
\hline 2418.52 & $\mathrm{CH}_{3} \mathrm{OH}$ & $10_{2}+9_{3}+$ & 165.4 & & -4.73 & $2.2(7)$ & JPL & & $97.1 \pm$ & $38.8 \pm 3.5$ \\
\hline 232683.93 & $\mathrm{CH}_{3} \mathrm{OCHO}$ & $19_{10,10}-18_{10,9} \mathrm{E}$ & 365.5 & 36.7 & -3.86 & - & JPL & & $97.6 \pm 0.1$ & 1.1 \\
\hline 232738.62 & $\mathrm{CH}_{3} \mathrm{OCHO}$ & $19_{8,11}-18_{8,10} E$ & 342.0 & 41.6 & -3.80 & - & JPL & & & $11.0 \pm 0.8$ \\
\hline 232754.71 & $\mathrm{H}_{2} \mathrm{C}^{34} \mathrm{~S}$ & $7_{1,7}-6_{1,6}$ & 57.9 & 55.9 & -3.74 & $0(6)^{(a)}$ & CDMS & $4.9 \pm 0.6$ & $96.8 \pm 0.3$ & $12.0 \pm 2.0$ \\
\hline & & $18_{3}+-17_{4}+$ & 446.54 & 5.46 & -4.66 & - & JPL & & $1 \pm 0.1$ & $50.4 \pm 3.3$ \\
\hline 2790.02 & $\mathrm{C}_{2} \mathrm{H}_{5} \mathrm{CN}$ & $26_{3,24}-25_{3,25}$ & 161.0 & 380.0 & -2.98 & - & JPL & $5.6 \pm 0.4$ & $97.0 \pm 0.1$ & $46.5 \pm 5.1$ \\
\hline 32836.17 & $\mathrm{CH}_{3} \mathrm{OCHO}$ & $19_{8,12}-18_{8,11} \mathrm{~A}$ & 341.8 & 41.6 & -3.81 & - & JPL & $3.5 \pm 0.2$ & $97.0 \pm 0.1$ & $8.5 \pm 0.7$ \\
\hline 2839.68 & $\mathrm{CH}_{3} \mathrm{OCHO}$ & $19_{8,11}-18_{8,10} \mathrm{~A}$ & 341.8 & 41.6 & -3.80 & - & JPL & $4.2 \pm 0.7$ & $97.5 \pm 0.3$ & $9.5 \pm 2.2$ \\
\hline 2865.05 & $\mathrm{CH}_{3} \mathrm{COCH}_{3}$ & $17_{8,10}-16_{7,9} \mathrm{EE}$ & 114.8 & 1121.9 & -3.53 & - & JPL & & $97.4 \pm 0.5$ & $5.0 \pm 1.1$ \\
\hline 2945.80 & $\mathrm{CH}_{3} \mathrm{OH}$ & $10_{-3}-11_{-2} \mathrm{E} 2$ & 190.4 & 3.0 & -4.67 & $1.6(7)$ & JPL & & & $78.7 \pm 6.3$ \\
\hline 2962.32 & $\mathrm{C}_{2} \mathrm{H}_{5} \mathrm{CN}$ & $6_{10}-25_{10}$ & 6 & 328.4 & -3.04 & - & JPL & & & $37.3 \pm 3.2$ \\
\hline 2967.57 & $\mathrm{C}_{2} \mathrm{H}_{5} \mathrm{CN}$ & $26_{9}-25_{9}$ & 240.9 & 339.2 & -3.03 & - & JPL & & $97.0 \pm 0.3$ & $44.2 \pm 8.3$ \\
\hline 32975.51 & $\mathrm{C}_{2} \mathrm{H}_{5} \mathrm{CN}$ & $26_{11}-25_{11}$ & 285.2 & 316.4 & -3.06 & - & JPL & & & $34.4 \pm 1.2$ \\
\hline 32998.74 & $\mathrm{C}_{2} \mathrm{H}_{5} \mathrm{CN}$ & $26_{8}$ & 222.0 & 348.9 & -3.01 & - & JPL & & & $36.7 \pm 5.9$ \\
\hline 3002.70 & $\mathrm{C}_{2} \mathrm{H}$ & $26_{12}-25_{12}$ & & & -3.07 & - & JPL & & & 30.3 \\
\hline 1.09 & $\mathrm{C}_{2} \mathrm{H}_{5} \mathrm{CN}$ & $26_{13}-25_{13}$ & 338.3 & 289.1 & -3.09 & - & JPL & & & $22.8 \pm 2.4$ \\
\hline 37 & $\mathrm{C}_{2} \mathrm{H}_{5} \mathrm{CN}$ & $26_{7}-25_{7}$ & 205.4 & 357.5 & -3.00 & - & JPL & & & $42.6 \pm 3.3$ \\
\hline 8.86 & $\mathrm{C}_{2} \mathrm{H}$ & $26_{14}-25_{14}$ & & 273.6 & -3.12 & - & JPL & & & 21.0 \\
\hline .36 & $\mathrm{CH}_{3} \mathrm{OCH}_{3}$ & $22_{2,21}-22_{1,22}$ & 232.9 & 135.6 & -4.56 & - & CDMS & & & $17.1 \pm 3.7$ \\
\hline 6.79 & $\mathrm{CH}_{3} \mathrm{OCHO}$ & $19_{4,16}-18_{4,15} \mathrm{~A}$ & 123.2 & 48.0 & -3.74 & - & JPL & & & $41.1 \pm 5.7$ \\
\hline 6.79 & $\mathrm{CHO}$ & $19_{16,3}-18_{16,2} \mathrm{~A}$ & 281.8 & 14.8 & -4.25 & - & JPL & & & $11.0 \pm 1.6$ \\
\hline 8.59 & $\mathrm{CHO}$ & $19_{16,4}-18_{16,3} E$ & 281.8 & 14.8 & -4.25 & - & JPL & & & $11.4 \pm 1.1$ \\
\hline 7.94 & $\mathrm{C}_{2} \mathrm{H}$ & $26_{17}-25_{17}$ & 470.6 & 220.7 & -3.21 & - & JPL & & & 2.0 \\
\hline 0.12 & $\mathrm{CH}_{3} \mathrm{OCHO}$ & $9_{15,5}-18_{15,4} \mathrm{~A}$ & 261.3 & & -4.14 & - & JPL & & & 20.1 \\
\hline .78 & $\mathrm{CHO}$ & $19_{15,4}-18_{15,3} E$ & 261.3 & & -4.14 & - & JPL & & & 13.2 \\
\hline 1.21 & $\mathrm{HO}$ & $19_{15,5}-18_{15,4} E$ & .3 & & -4.14 & - & JPL & & & 10.1 \\
\hline 66 & $\mathrm{CHO}$ & $19_{14,6}-18_{14,5} \mathrm{~A}$ & .1 & & -4.06 & - & JPL & & & 34.9 \\
\hline .43 & $\mathrm{CHO}$ & $19_{14,6}-18_{14,5} E$ & 24 & & -4.06 & - & JPL & & & 15.7 \\
\hline .10 & $\mathrm{CN}$ & $26_{5,22}-25_{5,21}$ & 17 & 371.1 & -2 & - & JPL & & & 42.4 \\
\hline & $\mathrm{CN}$ & $26_{5,21}-25_{5,20}$ & & 3 & -2.98 & - & JPL & & & 41.5 \\
\hline 24 & $\mathrm{CHO}$ & $19_{7,12}-18_{7,11} \mathrm{~A}$ & .0 & & -3.78 & - & JPL & & & 20.1 \\
\hline & $\mathrm{OH}$ & $13_{5,8}-13_{4,9}$ & & & -4.15 & - & JPL & & & 15. \\
\hline & $\mathrm{CH}_{3}$ & $25_{5,20}-25_{4,21}$ & & 9 & -4.13 & - & CDMS & & & 35.1 \\
\hline & $\mathrm{CHO}$ & $19_{12,7}-18_{12,6} E$ & 207.6 & & -3.94 & - & JPL & & & 19.6 \\
\hline & CHO & $19_{12,7}-18_{12,6} \mathrm{~A}$ & & & -3.94 & - & JPL & & .4 & 64.6 \\
\hline 0.98 & $\mathrm{CHO}$ & $19_{12,8}-18_{12,7} E$ & 207.6 & & -3.94 & - & JPL & & & 19.5 \\
\hline 233727.94 & $\mathrm{CH}_{3}^{18} \mathrm{OH}$ & $5_{1,4}-4_{1,3} \mathrm{~A}$ & & & -4.28 & $5(5)$ & CDMS & & 0.2 & 14.8 \\
\hline 734.72 & $(\mathrm{O}) \mathrm{NH}_{2}$ & & & & -3.03 & - & & & & 17.4 \\
\hline 5.61 & $\mathrm{C}(\mathrm{O}) \mathrm{NH}_{2}$ & 4,7 & & 124.8 & -3.03 & - & CDMS & & 0.1 & 13.5 \\
\hline 3753.96 & $\mathrm{H}_{3} \mathrm{OCHO}$ & $18_{4,14}-17_{4,13} E$ & & & -3.74 & - & JPL & & & 45.4 \\
\hline 7.52 & DCHO & $13 \mathrm{~A}$ & & & -3.74 & - & JPL & & & 35.3 \\
\hline 5.67 & $\mathrm{H}_{3} \mathrm{OH}$ & $18_{3}--17_{4}-$ & 446.59 & & -4.66 & - & JPL & & & $49.2 \pm 5.9$ \\
\hline 845.23 & $\mathrm{CH}_{3} \mathrm{OCHO}$ & $19_{11,8}-18_{11,7} E$ & & & -3 & - & JPL & & 97.3 & 26.4 \\
\hline 3854.29 & $\mathrm{I}_{3} \mathrm{OCHO}$ & $1,8 \mathrm{~A}$ & & & -3.89 & - & JPL & & 97.1 & 28.6 \\
\hline 3867.19 & $\mathrm{CH}_{3} \mathrm{OCHO}$ & $19_{11,9}-18_{11,8} E$ & 192.4 & & -3 & - & JPL & & & 20.6 \\
\hline 233896.58 & $\mathrm{HC}(\mathrm{O}) \mathrm{NH}_{2}$ & & 94.1 & 133.1 & -3.03 & - & CDMS & & 97.3 & 19.8 \\
\hline 916.95 & & $13_{3}-14_{4}-$ & 868.5 & 2. & -5.26 & - & JPL & & 97.1 & 13.3 \\
\hline 1.12 & $\mathrm{H}_{5} \mathrm{OH}$ & 12 & 107.9 & 12.8 & -4.15 & - & JPL & & 97.2 & 18.3 \\
\hline 2340 & $\mathrm{H}_{3} \mathrm{OH}$ & 4 & 48.3 & 3.9 & -4.28 & $1(7)^{(c}$ & CDMs & & 96.9 & 35.3 \\
\hline 2 & & & & & & - & & & & 28.2 \\
\hline 2341 & & & & & & - & & & & 35.5 \\
\hline 2341 & $\mathrm{CHO}$ & & & & & - & & & 97. & 27.6 \\
\hline 234255.16 & $\mathrm{OH}$ & 1 & 96 & 11.6 & & - & JPL & & 97.1 & 12.2 \\
\hline 234315.50 & $\mathrm{HC}(\mathrm{O}) \mathrm{NH}_{2}$ & 11 & & 133.1 & & - & CDMS & & & $17.4 \pm 2.4$ \\
\hline 234336.11 & $\mathrm{CH}_{3} \mathrm{O}$ & $19_{6,14}-18$ & 323.5 & & -3.76 & - & & & 97.2 & $14.5 \pm 2.2$ \\
\hline 1.27 & $\mathrm{HO}$ & A & & & -3 & - & JPL & & 97.0 & 16.9 \\
\hline 234406.45 & $\mathrm{C}_{2} \mathrm{H}_{5} \mathrm{OH}$ & & & & & - & JPL & & 97.2 & $11.2 \pm 0.7$ \\
\hline 234423.96 & $\mathrm{C}_{2} \mathrm{H}_{5} \mathrm{CN}$ & $26_{4,22}-25_{4,21}$ & 169.1 & 376.3 & -2.98 & - & JPL & $5.3 \pm 0.1$ & $97.2 \pm 0.1$ & $42.9 \pm 1.4$ \\
\hline
\end{tabular}


Table A.2. Same as Table A.1 but towards core \#6.

\begin{tabular}{|c|c|c|c|c|c|c|c|c|c|c|}
\hline $\begin{array}{c}\text { Frequency } \\
(\mathrm{MHz})\end{array}$ & Molecule & $\begin{array}{c}\text { Transition } \\
\quad J=\end{array}$ & $\begin{array}{l}E_{\text {up }} \\
(\mathrm{K})\end{array}$ & $\begin{array}{l}S \mu^{2} \\
\left(\mathrm{D}^{2}\right)\end{array}$ & $\begin{array}{c}\log \left(A_{\mathrm{ij}}\right) \\
\left(\mathrm{s}^{-1}\right)\end{array}$ & $\begin{array}{c}n_{\text {crit }} \\
\left(\mathrm{cm}^{-3}\right)\end{array}$ & Database & $\begin{array}{l}\text { Line width } \\
\left(\mathrm{km} \mathrm{s}^{-1}\right)\end{array}$ & $\begin{array}{l}\text { Velocity } \\
\left(\mathrm{km} \mathrm{s}^{-1}\right)\end{array}$ & $\int_{\left(\mathrm{K} \mathrm{km} \mathrm{s}^{-1}\right)} T_{\mathrm{mb}} \mathrm{d} v$ \\
\hline 216 & $\mathrm{H}_{3} \mathrm{C}$ & $2,18-18$ & 3 & & & - & $\mathrm{JP}$ & 9 & .4 & .5 \\
\hline 216115.57 & $\mathrm{CH}_{3} \mathrm{OCHO}$ & $19_{2,18}-18_{2,17} \mathrm{~A}$ & 109.3 & 49.4 & & - & JPL & & & \\
\hline 216147.36 & $\mathrm{OC}^{33} \mathrm{~S}$ & $18-17$ & 98.6 & 9.2 & -4.04 & $.3(6)$ & CDMS & $2.1 \pm 0.6$ & $95.4 \pm 0.3$ & $1.1 \pm 0.3$ \\
\hline 216210.91 & $\mathrm{CH}_{3} \mathrm{OCHO}$ & $19_{1,18}-18_{1,17} \mathrm{E}$ & 109.3 & 49.4 & & - & JPL & & & \\
\hline 216216.54 & $\mathrm{CH}_{3} \mathrm{OCHO}$ & $19_{1,18}-18_{1,17} \mathrm{~A}$ & 109.3 & 49.4 & -3.83 & - & JPL & & $95.9 \pm$ & $1.6 \pm$ \\
\hline 217104.98 & $\operatorname{Sin} v-0$ & & 31 & 48.0 & & 48 & & & & \\
\hline 217238.54 & $\mathrm{DCN}$ & $3-2$ & 20.9 & 80.5 & & - & MMS & & & 0.4 \\
\hline 81 & $\mathrm{O}^{13} \mathrm{CS}$ & $18-17$ & 5 & 9.2 & -4.52 & $1 / 5$ & 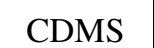 & $2.1 \pm 0.4$ & 95. & $2.0 \pm 0.3$ \\
\hline & & $3_{0,3}-$ & & & & 2.6 & & & & \\
\hline & $\mathrm{CH}_{3} \mathrm{OCHO}$ & $17_{3,14}-1$ & & & & - & & & & \\
\hline 218297.89 & $\mathrm{CH}_{3} \mathrm{OCHO}$ & $17_{3,14}-16_{3,13} \mathrm{~A}$ & 99.7 & 43.6 & & - & JPL & & & $2.4 \pm 0.4$ \\
\hline 218324.72 & $\mathrm{HC}_{3} \mathrm{~N}$ & $24-23$ & 131.0 & 334.2 & & $1.7(7$ & $\mathrm{CD}$ & & & $10.7 \pm 0.9$ \\
\hline 219560.35 & $\mathrm{C}^{18} \mathrm{O}$ & $2-1$ & 15.8 & 0.02 & -6.22 & o o(3) (a) & 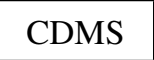 & $105(b)$ & $055(b)$ & $>14^{(b)}$ \\
\hline 53 & ${ }^{13} \mathrm{CO}$ & $1,2-21$, & 32.9 & & & $2.3(6)^{(a)}$ & & & & \\
\hline 44 & $\mathrm{~s} O$ & $6_{5}-5_{4}$ & 350 & 14.0 & & 2.3 & $\mathrm{C}$ & 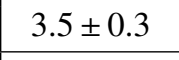 & .1 & $18.3 \pm 1.0$ \\
\hline 30315.79 & $\mathrm{H}_{3} \mathrm{CHO}$ & $12_{2,11}-11_{2,10} \mathrm{E}$ & 81.1 & 147.4 & -3.38 & - & JPI & $.9 \pm 1.1$ & $95.3 \pm 0.2$ & $3.5 \pm 1.3$ \\
\hline 538.00 & $\mathrm{CO}$ & $2-1$ & 16.6 & 0.02 & & 1.1( & & - & - & \\
\hline & & & & & & & & 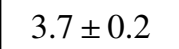 & & .4 \\
\hline & & & & & & $4.3(6)$ & & & & \\
\hline 9.90 & $\mathrm{CH}_{3} \mathrm{CHO}$ & $7-11_{6}$ & & 113.9 & & - & & & & 2.7 \\
\hline .11 & $\mathrm{H}$ & $10_{2}--9_{3}-$ & & & & $2.5(7$ & &  & & \\
\hline 231467.50 & $\mathrm{CH}_{3} \mathrm{CHO}$ & $12_{4,8}-11_{4,7} \mathrm{E}$ & 108.4 & 135.0 & & - & JPL & & & 0.2 \\
\hline 231506.29 & $\mathrm{CH}_{3} \mathrm{CHO}$ & $12_{4,9}-11_{4,8} \mathrm{E}$ & 108.2 & 135.0 & & - & JPL & & $95.9 \pm 0.2$ & \\
\hline & c & & & & & - & & & & \\
\hline & & $12_{3,10}-11_{3,9} \mathrm{E}$ & & & & - & & & & \\
\hline 231987.93 & $\mathrm{CH}_{3} \mathrm{OCH}_{3}$ & $13_{0,13}-12_{1,12} \mathrm{AE}$ & 80.9 & 101.9 & & - & & & & 0.4 \\
\hline 232418.52 & $\mathrm{CH}_{3} \mathrm{OH}$ & $10_{2}+-9_{3}+$ & 165.4 & 2.68 & -4.73 & $2.2(7)$ & JPL & 6 & 96.2 & 1.3 \\
\hline & & $\mathrm{E} 2$ & & & 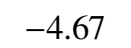 & 1.6( & & & & \\
\hline 6.79 & $\mathrm{CH}_{3} \mathrm{OCHO}$ & $1,15 \mathrm{~A}$ & 123.2 & 48.0 & & - & JPL & & & \\
\hline 233753.96 & $\mathrm{CH}_{3} \mathrm{OCHO}$ & $18_{4,14}-1$ & 114.4 & 45.8 & & - & JPL & \pm & & .7 \\
\hline & $\mathrm{CH}_{3} \mathrm{OCHO}$ & $18_{4,14}-17_{4,13} \mathrm{~A}$ & 114.4 & 45.8 & & - & & & & \\
\hline 234011.58 & ${ }^{13} \mathrm{CH}_{3} \mathrm{OH}$ & $5_{1,5}-4_{1,4}++$ & 48.3 & 3.9 & -4.28 & $1.1(7)^{(a)}$ & CDMS & $5.2 \pm 0.5$ & $96.5 \pm 0.2$ & $5.2 \pm 1.8$ \\
\hline
\end{tabular}

Notes. All observational values are integrated over the continuum core. ${ }^{(a)}$ Collision rate value from the main isotopologue. ${ }^{(b)}$ The line is selfabsorbed or filtered. The values correspond to the zero-base line width, the velocity of the line maximum, and the integration of the positive $T_{\mathrm{mb}}$ values. 
J. Molet et al.: Molecular analysis of a high-mass prestellar core candidate in W43-MM1

Table A.3. Column densities in core \#3 estimated for a source size of 1000 au and a temperature of $190 \mathrm{~K}$.

\begin{tabular}{|c|c|}
\hline Molecule & $N\left(\mathrm{~cm}^{-2}\right)$ \\
\hline $\mathrm{C}^{18} \mathrm{O}$ & $>8.4(17)$ \\
\hline $\mathrm{CH}_{3} \mathrm{OH}$ & $1.4(18)$ \\
\hline${ }^{13} \mathrm{CH}_{3} \mathrm{OH}$ & $2.8(17)$ \\
\hline $\mathrm{CH}_{3} \mathrm{CHO}$ & $3.8(16)$ \\
\hline${ }^{13} \mathrm{CS}$ & $3.2(15)$ \\
\hline $\mathrm{CH}_{3} \mathrm{OCH}_{3}$ & $4.7(17)$ \\
\hline $\mathrm{CH}_{3} \mathrm{OCHO}$ & $3.8(17)$ \\
\hline OCS & $1.0(17)$ \\
\hline $\mathrm{O}^{13} \mathrm{CS}$ & $1.2(16)$ \\
\hline $\mathrm{OC}^{33} \mathrm{~S}$ & $5.5(15)$ \\
\hline $\mathrm{SiO} v=0$ & $>1.9(15)$ \\
\hline SO & $1.5(16)$ \\
\hline $\mathrm{H}_{2} \mathrm{CO}$ & $>2.0(16)$ \\
\hline $\mathrm{H}_{2}^{13} \mathrm{CO}$ & $7.8(15)$ \\
\hline $\mathrm{HC}_{3} \mathrm{~N}$ & $2.4(15)$ \\
\hline $\mathrm{DCN}$ & $1.5(15)$ \\
\hline $\mathrm{CO}$ & $>2.1(19)$ \\
\hline $\mathrm{CH}_{3}^{18} \mathrm{OH}$ & $8.2(16)$ \\
\hline${ }^{13} \mathrm{CH}_{3} \mathrm{CN}$ & $1.9(15)$ \\
\hline $\mathrm{HC}(\mathrm{O}) \mathrm{NH}_{2}$ & $3.9(15)$ \\
\hline $\mathrm{C}_{2} \mathrm{H}_{5} \mathrm{OH}$ & $7.2(16)$ \\
\hline $\mathrm{H}_{2} \mathrm{C}^{34} \mathrm{~S}$ & $4.0(15)$ \\
\hline $\mathrm{CH}_{3} \mathrm{COCH}_{3}$ & $9.0(16)$ \\
\hline $\mathrm{C}_{2} \mathrm{H}_{3} \mathrm{CN}$ & $8.3(15)$ \\
\hline $\mathrm{C}_{2} \mathrm{H}_{5} \mathrm{CN}$ & $1.7(16)$ \\
\hline \multicolumn{2}{|c|}{ Column densities estimated from the isotopologues } \\
\hline $\mathrm{CH}_{3} \mathrm{OH}$ & $2.0(19)$ \\
\hline $\mathrm{CS}$ & $1.4(17)$ \\
\hline OCS & $5.2(17)$ \\
\hline $\mathrm{H}_{2} \mathrm{CO}$ & $3.5(17)$ \\
\hline $\mathrm{CO}$ & $>3.8(19)$ \\
\hline
\end{tabular}

Notes. $a(b)=a \times 10^{b}$. 

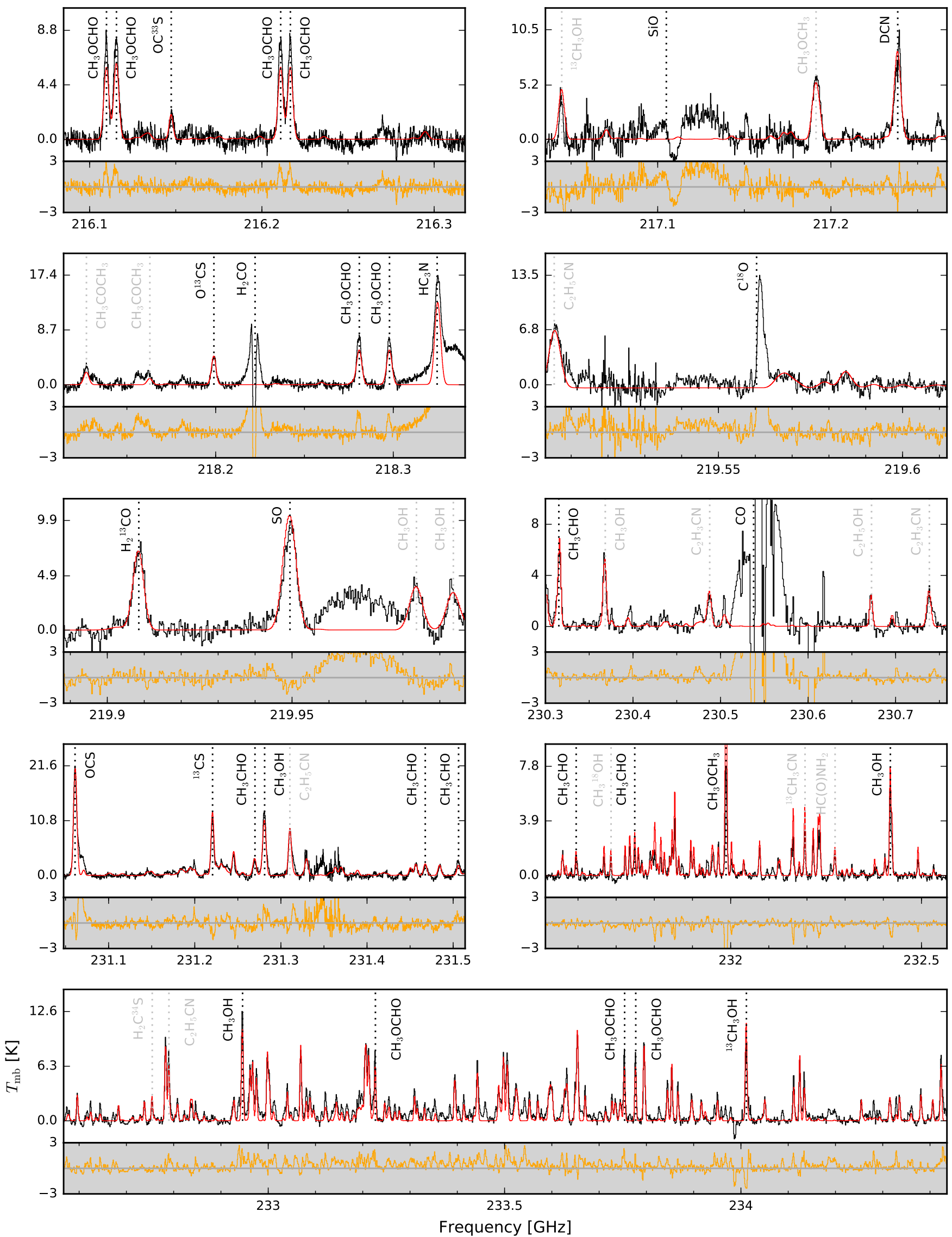

Fig. A.1. Observed spectra (in black), synthetic spectra (in red) and residuals (in orange) towards core \#3 for all the ALMA bands. The observed spectra are integrated over the continuum cores (see Table 2). All the molecular lines detected in core \#6 (see Table A.2) are indicated by black dotted lines and some of the additional molecular lines detected in core \#3 are indicated in grey. The parameters used for the synthetic spectra are listed in Table 3. The Cycle 3 spectral band Cont. 1, which overlaps with Cycle 2 data Cont. 2, is ignored here. 

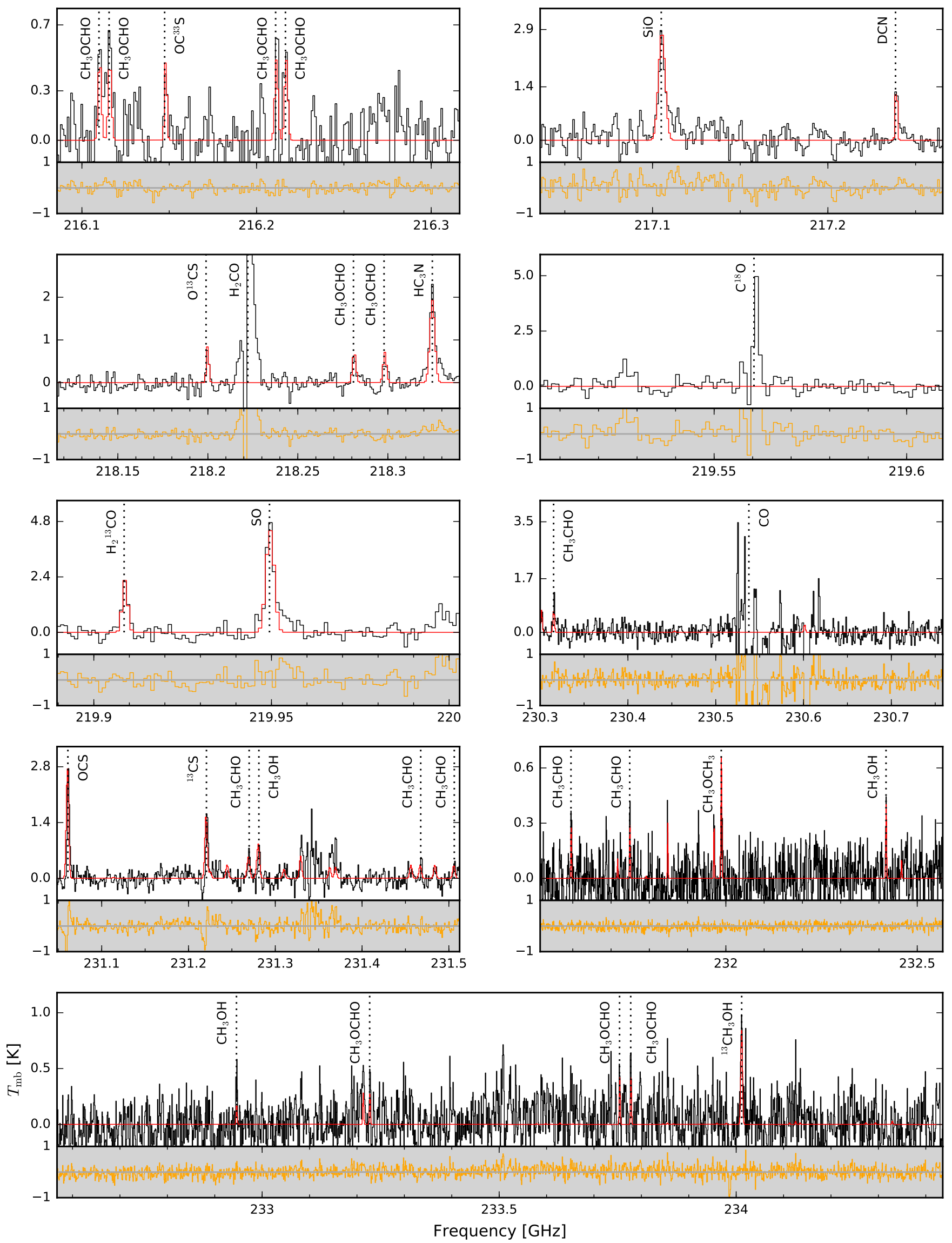

Fig. A.2. Same as Fig. A.1 but for source \#6. The spectra are Hanning smoothed to the same frequency resolution, $\Delta f=0.976 \mathrm{MHz}$. The synthetic spectra are calculated for a temperature of $30 \mathrm{~K}$, which corresponds to the very beginning of the protostellar phase. 